\title{
Unpacking the Long Run Effects of Tariff Shocks: New Structural Implications from Firm Heterogeneity Models
}

\author{
Alan Spearot* \\ University of California - Santa Cruz
}

July 2015

\begin{abstract}
I derive a novel solution for the general equilibrium effects of tariffs that is robust to heterogeneity across industries and countries, and is a function of only aggregate trade data and country-by-industry Pareto shape parameters. Using the model to evaluate tariff shocks, I show that while most countries lose by removing observed tariffs unilaterally, India, Japan, Korea, and the US gain by doing so, which suggests inefficient tariff discrimination. In evaluating multilateral shocks, observed tariff cuts over 1994-2000 benefit $69 \%$ of countries, with these benefits skewed toward developing nations. In contrast, removing all post-2000 tariffs benefit the developed.
\end{abstract}

Key Words: Firm-heterogeneity, Long Run, General Equilibrium, Productivity Estimation, Tariffs, Trade agreements

Tariff liberalization is often cited as a way to provide welfare gains through a variety of mechanisms. For example, if domestic firms are charging mark-ups above marginal cost, trade liberalization can discipline domestic firms either by lowering the price of imported goods or making feasible the import of new varieties. Further, depending on the nature of the liberalization, consumers may enjoy increased consumption opportunities through higher real wages.

*Department of Economics, 1156 High Street, Santa Cruz CA, 95064. Phone: +1 (831) 459-1530. Email: acspearot@gmail.com. I thank two referees and many colleagues at seminars for helpful comments. 
However, despite the theoretical potential of tariff liberalization, and trade agreements more generally, it is very difficult to predict their true effects. Primarily, this due to trade agreements involving a large set of countries and sectors, with each varying in a variety of unobservable ways. This is especially the case if variation in country-level characteristics, such as productivity distributions, lead certain countries to be less responsive to shocks and the actions of other firms. For example, although a regional trade agreement like NAFTA may seem very simple, if the underlying distribution of firms is different across Canada, Mexico, and the US, entry and exit rates will vary across locations, complicating any assessment of the shock 1 Further, if factor markets are more constrained in one of the countries party to the agreement, then heterogeneous effects of the agreement may arise.2 And arguably, the most complicated are the effects of the trade agreements on outsiders. For example, if the signing of NAFTA made it less profitable for firms from the EU to serve the North American market, then this plays into entry decisions within the EU, which may affect trade flows to other markets, and so on.

Ultimately, the global economy is an extremely large system of heterogeneous countries and industries, with entry choices and factor markets linked through trade flows, large and small, and a patchwork of both multilateral and discriminatory policies. How do we measure the effects of trade shocks within such a large, complex system? Who are the winners and losers from past and proposed trade agreements?

In this paper, I develop new tools for evaluating the effects of trade shocks that require relatively few assumptions over underlying modeling parameters. Specifically, I examine the long-run effects of tariffs within a common firm-heterogeneity model, but in the presence of rich cross-country heterogeneity. The primary theoretical contribution is showing that while the long-run equilibrium depends on a host of unobserved parameters (such as productivity distributions and tastes), there exists a simple structural relationship between tariff shocks and endogenous outcomes that is a function of only a bilateral trade matrix and a vector of country-by-industry Pareto distribution shape parameters. Using a new class of trade growth specification, I structurally estimate these shape parameters using trade flows and tariff cuts subsequent to the Uruguay Round. Armed with the shape estimates, I use trade data to

\footnotetext{
${ }^{1}$ Initially discussed in Venables (1985), a common prediction in many new trade models is one in which unilateral tariff liberalization decreases competition in the liberalizing market due to a particularly strong exit of firms. Further, the response of free entry to tariffs is documented from a historical perspective in Inwood \& Keay (2013) for the Canadian Pig Iron Industry.

${ }^{2}$ Any adjustment in the labor market (Demidova \& Rodríguez-Clare (2015)) or the nature of competition (de Blas \& Russ (2015)) can produce additional mechanisms that change the long-run effects of liberalization.
} 
compute counterfactuals related to tariff shocks. The results indicate that both across-sector and within-sector variation in shape parameters matters for the qualitative and quantitative welfare effects of tariff shocks. Further, I show that many large trade agreements do not benefit all member countries.

I introduce these issues by employing an amended version of Melitz \& Ottaviano (2008), which utilizes non-nomothetic preferences and produces variable demand elasticities at the firm-level similar to those empirically supported in Foster, Haltiwanger \& Syverson (2008). However, to allow for wage effects, I do away with the outside good, which brings the model in-line with the CES side of the literature 3 The main innovation in my framework is allowing for variation in the shape of the Pareto distribution that governs productivity draws by country and industry $\left.\right|_{4} ^{4}$ Indeed, shape heterogeneity in the presence of elasticity variation is important in that it can produce empirically documented tariff elasticity differences across exporting countries (Spearot (2013)), as well as match the empirical relationship between larger export flows and larger surviving exporting firms. Further, shape variation affects average profit margins of surviving firms, the probability of survival itself, and the elasticity of survival to shocks, all of which critical for entry decisions. Finally, as elasticity variation can support optimal discrimination (Saggi \& Sara (2008)), quantifying the impact of tariffs with such variation is of significant policy interest.

However, shape heterogeneity severely complicates the assessment of long-run equilibrium conditions. Specifically, since the elasticity of the extensive margin to shocks now varies by location, the system of free entry and labor market clearing conditions is highly non-linear, and may be satisfied by multiple candidate solutions on the interior 5 To work around this issue, I exploit a simple link between expected profits, expected labor demand, and expected trade values. Specifically, when using the Pareto distribution, these expected values are proportional via the mark-up to reported bilateral trade values, and this proportional mark-up is a simple function of the supplying country's Pareto shape parameter. Consequently, a percent shock to a tariff or equilibrium parameter within expected profits

\footnotetext{
${ }^{3}$ For related CES models, see Melitz (2003), Helpman, Melitz \& Yeaple (2004), Chaney (2008), Arkolakis, Costinot \& Rodríguez-Clare (2011), and Melitz \& Redding (2015). Atkeson \& Burstein (2008) also produces variable demand elasticities, but the Cournot competition assumption is intractable in my setting.

${ }^{4}$ This is consistent with the class of productivity variation modeled in Demidova (2008), but different from variation in the upper bound of the cost distribution as in Melitz \& Ottaviano (2008), Hsieh \& Ossa (2015), and Bombardini, Kurz \& Morrow (2012).

${ }^{5}$ Similar complications would arise in other models with adjustments that are not elasticity neutral for example, Helpman, Melitz \& Rubinstein (2008). However, in these papers free entry is not modeled. Other multi-region models, such as Combes, Duranton, Gobillon, Puga \& Roux (2012), do not allow for such productivity shape heterogeneity.
} 
or labor demand is also proportional to trade value to that market. Hence, the Jacobian matrix of a system of equilibrium conditions is both simple to characterize and structurally linked to observable data. Using this link, I show that despite the highly non-linear system of equilibrium conditions, the general equilibrium response to trade shocks is a linear function of the matrix of trade flows and a vector of productivity shape parameters. Further, I show using the same proportionality results how one can derive a simple and empirically feasible measure of representative consumer well-being to use in policy evaluation. Indeed, productivity shape variation is important for this measure, as all else equal, consumers will be better off spending a unit of income on varieties from countries with a better shape of firms, that is, active firms that charge lower average prices.

To evaluate the model empirically, I outline a simple procedure to estimate a logdifferentiated trade flow equation, and estimate the model using trade flow and tariff cut data that occurred subsequent to the period of Uruguay Round tariff negotiations. To my knowledge I provide the first estimates of country-by-industry Pareto shape parameters using a common dataset, and despite using aggregate data, the estimates are within sensible bounds and in the vicinity of those assumed in the literature 6 There is significant variation in productivity shape across industries, which is a feature of the results presented in Caliendo \& Parro (2015). However, unlike the existing literature, I find that there is significant within-industry heterogeneity in productivity shape across countries. This variation is sensible, with the US having the most favorable shape of firms - significantly better than average in many industries - and countries such as Bangladesh and Mozambique have the least favorable shape of firms. The shape estimates associate favorably to external performance measures from the World Management Survey (Bloom \& Van Reenen (2006)) and average firm-size data from the Exporter Dynamics Database in Cebeci, Fernandes, Freund \& Pierola (2012).

Armed with the shape estimates, I return to the structural results from the model to study the partial effects of productivity heterogeneity in guiding the welfare effects of tariff shocks. Compared to a setting with no productivity variation across countries, the results indicate that accounting for across-sector variation in productivity shape changes the qualitative welfare effects of a unilateral $10 \%$ increase in tariffs by the US for $21 \%$ of countries. From this point of across-sector heterogeneity, adding within-sector shape heterogeneity changes

\footnotetext{
${ }^{6}$ See Eaton, Kortum \& Kramarz (2011) and Di Giovanni, Levchenko \& Ranciere (2011). Okubo \& Tomiura (2014) do provide regional estimates of productivity distributions in Japan using firm-level data, and find that productivity is more left-skewed in agglomerated regions. Newer work is moving toward using the log-normal distribution to better match the moments of the data. See Head, Mayer \& Thoenig (2014).
} 
the qualitative effects of this unilateral tariff shock for $4 \%$ of countries. For $34 \%$ of countries in the sample, including within-industry shape variation amplifies the negative effect of higher US tariffs. These countries tend to have a less favorable shape of firms and hence a larger tariff elasticity, which is consistent with micro-evidence on a differential effect of US tariffs (Spearot (2013)).

Next, I evaluate a unilateral reduction in tariffs to zero by each country. As tariffs are zero for some countries (eg. via NAFTA or GSP preferences), and zero for some products (MFN reductions through the Uruguay Round), this is an asymmetric, unilateral liberalization episode. While most countries lose by removing tariffs unilaterally, India, Japan, Korea, and the US gain by doing so, which suggests a significant degree of tariff misallocation through inefficient discrimination.

In evaluating multilateral counterfactuals, I find that larger tariff shocks (such as those that occurred over 1994-2000) benefited $69 \%$ of countries, with these benefits skewed toward developing nations. Complete tariff liberalization from year 2000 levels produces a similar result, with $69 \%$ countries benefiting, but with the benefits skewed toward the developed. However, only $54 \%$ of countries gain from both, which may suggest why some supporters of the Uruguay Round and associated cuts may dislike future cuts. I also find that proposed trade agreements, such as the Trans-Pacific Partnership, have disparate welfare effects both within and outside of the agreement, with agreement countries Chile and especially Malaysia experiencing a welfare loss.

Finally, in a technical appendix, I derive an equivalent model using CES preferences, and show that the equilibrium and qualitative welfare effects are equivalent when there is no shape (and hence elasticity) variation. Otherwise, the models yield different aggregate equilibrium conditions and welfare formulae. For each trade agreement studied above, the welfare effects are qualitatively different for $10 \%$ of countries.

Overall, this paper adds new tools in the evaluation of tariffs and other trade shocks. The structural estimation is related to Eaton \& Kortum (2002), Eaton, Kortum \& Kramarz (2011), Caron, Fally \& Markusen (2015), Edmond, Midrigan \& Xu (2015), and Breinlich \& Cuñat (2015), though it is most like Dekle, Eaton \& Kortum (2008), Caliendo \& Parro (2015), and especially Ossa (2014) in that changes to aggregate terms are a simple function of observable data. Indeed, like Ossa (2014), I evaluate the effects of tariffs using GTAP data. However, the simple relationship I uncover works through the proportionality of average profits, average labor demand, and average revenues, which is distinct from Dekle, Eaton \& Kortum (2008), Caliendo \& Parro (2015), and Ossa (2014), and may vary country-by- 
industry with the shape of the Pareto distribution. Hsieh \& Ossa (2015) also allow for country-by-industry heterogeneity, though focus on the support of the distribution rather than the shape. $]^{7}$ The paper also relates to the literature on optimal trade policy in the presence of firm delocation in Bagwell \& Staiger (2015), Ossa (2011), Bagwell \& Staiger (2012), and Bagwell \& Lee (2014).

Similar to Arkolakis, Costinot \& Rodríguez-Clare (2011), Arkolakis, Costinot, Donaldson \& Rodríguez-Clare (2012), Costinot \& Rodríguez-Clare (2013) and Burstein \& Cravino (2015), I derive clean results for the welfare effects of arbitrary shocks. Again, my paper exploits proportionality in average profits, revenues and labor demand at the bilateral level, which is similar to the aggregate restrictions in Arkolakis, Costinot \& Rodríguez-Clare (2011), and comparable to the empirical results in Costinot \& Rodríguez-Clare (2013). The Jacobian technique at the heart of my work has its origins in a two-country model from an online technical appendix in Spearot (2013), as well as the multi-country model without wage effects in Spearot (2014). Very new work in Allen, Arkolakis \& Takahashi (2014) uses a similar Jacobian technique to characterize the effects of shocks in a general gravity framework (along with providing a number of fundamental theorems related to gravity models). Their work primarily differs from my approach in that I explicitly study revenue generating tariffs, and I allow for non-nomothetic preferences in the presence of country-by-industry variation in shape parameters, both features being different from the class of models studied in their work. Further, the non-linear estimator described in section three is novel in trade, and necessary to estimate the shape differences at the core of my contribution.

\section{General Setup and Motivation}

To model consumers, I will utilize continuum-quadratic utility to represent preferences over varieties within industries, similar to Melitz \& Ottaviano (2008). However, to allow for wage effects, I will do away with the outside good, which is more closely related to general equilibrium oligopoly model in Neary (2009), and the CES literature more broadly. The novel contribution of this setup is to adjust the canonical firm-heterogeneity model to allow for differences in productivity distributions across supplying countries, and show how one can work with the model empirically to examine counterfactual tariff cuts and trade agreements.

\footnotetext{
${ }^{7}$ Recent work in Feenstra (2014) examines the role of the Pareto distribution bounds for the sources of gains from trade.
} 


\section{A Consumers}

Consumer preferences in each country are defined across industries, and then varieties within industries. Precisely, utility in country $l$ is written as:

$$
U_{l}=\prod_{i=1}^{I}\left(U_{i, l}\right)^{\beta_{i l}}
$$

where

$$
U_{i, l}=\theta_{i, l} \int_{\omega \in \Omega_{i, l}} q_{i, l}^{c}(\omega) d \omega-\frac{1}{2} \gamma_{i, l} \int_{\omega \in \Omega_{i, l}}\left(q_{i, l}^{c}(\omega)\right)^{2} d \omega
$$

In (1), industries are aggregated according to Cobb-Douglas weights, with $\sum_{i=1}^{I} \beta_{i l}=1$ for all $l$. In (1), $U_{i, l}$ is industry-level sub-utility, with utility over varieties as written in (2). Within each industry $i$ in country $l$, I adopt continuum quadratic preferences, where $\Omega_{i, l}$ defines the set of varieties available, $q_{i, l}^{c}(\omega)$ is the consumption of variety $\omega$ from industry $i$ by the representative consumer in $l$, and $\theta_{i, l}(>0)$ and $\gamma_{i, l}(>0)$ are industry-country specific utility parameters. Though each country has the same basic utility structure, the governing parameters are allowed to differ across countries and industries. However, all of this heterogeneity will be absorbed by the novel strategy used for tariff counterfactuals.

The budget constraint faced by the representative consumer in country $l$ is written as

$$
\sum_{i=1}^{I} \int_{\omega \in \Omega_{i, l}} p_{i, l}^{c}(\omega) q_{i, l}^{c}(\omega) d \omega \leq w_{l}+T_{l} / L_{l}
$$

where $w_{l}$ is wage income accruing to the representative consumer in $l$, and $T_{l} / L_{l}$ is tariff revenue $T_{l}$ evenly distributed across $L_{l}$ consumers.

Solving the consumer's maximization problem for variety $\omega$, and writing the Lagrange multiplier for the representative consumer in $l$ as $\lambda_{l}$, we get the following inverse Frisch demands for variety $\omega$.

$$
p_{i, l}^{c}(\omega)=\underbrace{\beta_{i l} \frac{U_{l}}{\lambda_{l} U_{i, l}}}_{1 / \lambda_{i l}}\left(\theta_{i, l}-\frac{\gamma_{i, l}}{L_{l}} q_{i, l}(\omega)\right)=\frac{1}{\lambda_{i l}}\left(\theta_{i, l}-b_{i, l} q_{i, l}(\omega)\right)
$$

In (4), $q_{i, l}(\omega)$ is total quantity sold of variety $\omega$ from industry $i$ to all consumers in $l$, and $b_{i, l}$ measures the "slope" of the aggregate demand curve for each variety from $i$ in $l$, which 
is $\gamma_{i, l}$ scaled inversely by the number of consumers in $l$. The actual slope will be affected by $\lambda_{i l}$, which we now discuss.

In $(4)$, all terms are multiplied by $\beta_{i l} \frac{U_{l}}{\lambda_{l} U_{i, l}}$, which results from substitution across industries in the upper-tier of the utility function. We label this entire term as $\frac{1}{\lambda_{i l} l}$, which consists of the marginal utility of income, $\lambda_{l}$, and marginal utility in industry $i, \beta_{i l} \frac{U_{l}}{U_{i l}}$. Intuitively, with additional consumption within a differentiated industry, or a tighter budget constraint, the willingness to pay falls for each variety. Hence, $\lambda_{i l}$ rises and inverse demand pivots downward. One of the main contributions of the paper shows how $\lambda_{i l}$ changes with tariffs, and how this effect can be written as a function of trade data and estimable parameters. This measure will also be linked to welfare in a similar fashion.

\section{B Firms}

The characterization of firms is relatively simple. Firms enter under uncertainty, paying a fixed entry cost $w_{j} F_{i j}$, where $F_{i j}$ is the fixed labor requirement for entry in industry $i$ and country $j$, and $w_{j}$ is the wage in country $j$. Upon entry, firms draw a firm-specific unit labor requirement $a$ from an industry-country-specific Pareto distribution, which I will detail shortly. Then, firms serve all profitable markets (amongst $M$ total markets) and earn profits. I introduce the firm's problem by backward induction.

\section{Post-entry Production}

Within industry $i$, a firm may sell one variety to each market, paying an ad-valorem tariff $\tau_{i j l}$ on the value of each unit sold from $j$ to $l$. Note that I allow this tariff to be negative, in that case implying an import subsidy, and that $\tau_{i j l}=0$ when $j=l$. The relationship between the consumer price for variety $\omega$ detailed in (4) and the price that the foreign producer of $i$ receives is $p_{i j l}^{c}(\omega)=t_{i j l} p_{i j l}^{s}(\omega)$, where $t_{i j l}=1+\tau_{i j l}$. This yields the following inverse demand function that the supplier of variety $\omega$ in industry $i$ from country $j$ uses to optimally set production for market $l$ :

$$
p_{i j l}^{s}(\omega)=\frac{1}{t_{i j l} \lambda_{i l}}\left(\theta_{i, l}-b_{i, l} q_{i j l}(\omega)\right) .
$$

Firms choose quantities to maximize profits, where the maximization problem for a firm producing variety $\omega$ from industry $i$ with unit labor requirement $a(\omega)$ exporting from $j$ to $l$ 
is written as:

$$
\pi_{i j l}(a(\omega))=\max _{q_{i j l}(\omega)}\left\{\frac{1}{t_{i j l} \lambda_{i l}}\left(\theta_{i l}-b_{i l} q_{i j l}(\omega)\right) \cdot q_{i j l}(\omega)-w_{j} a(\omega) q_{i j l}(\omega)\right\} .
$$

Suppressing $\omega$ 's for the remainder of the paper, the optimal quantity selling in industry $i$ from $j$ to $l$ is written as

$$
q_{i j l}(a)=\frac{\theta_{i l}-a w_{j} t_{i j l} \lambda_{i l}}{2 b_{i l}}
$$

producer revenues are written as

$$
v_{i j l}(a)=\frac{\theta_{i l}^{2}-\left(a w_{j} t_{i j l} \lambda_{i l}\right)^{2}}{4 b_{i l} t_{i j l}}
$$

and profits are written as

$$
\pi_{i j l}(a)=\frac{\left(\theta_{i l}-a w_{j} t_{i j l} \lambda_{i l}\right)^{2}}{4 b_{i l} t_{i j l}}
$$

Note that relative to "standard" models with iceberg trade costs, revenues and profits are scaled in the denominator by $t_{i j l}$, since there is a wedge between what the producer receives and the consumer pays 8

\section{Productivity and Entry}

Upon entry, firms draw their unit labor requirement $a$ from the following Pareto distribution with parameters that vary by country within each differentiated industry:

$$
g_{i j}(a)=k_{i j} \frac{a^{k_{i j}-1}}{\left(a_{i j}^{m}\right)^{k_{i j}}} \quad, \quad a \in\left[0, a_{i j}^{m}\right]
$$

In (5), there are two-layers of productivity heterogeneity across countries, within industries. First, slightly more standard in the literature is variation in the upper-bound on the distri-

\footnotetext{
${ }^{8}$ Note that this treatment of tariffs is different from Costinot \& Rodríguez-Clare (2013) which treats tariffs as a cost shifter, with no wedge between consumer revenue and producer revenue. When tariffs create a wedge between consumer and producer prices, the trade elasticity + domestic share formula from Arkolakis, Costinot \& Rodríguez-Clare (2011) requires one additional elasticity parameter (see page 31, footnote 30 , of Costinot \& Rodríguez-Clare (2013)). I produce a similar result in the online appendix, where I derive an equivalent model with shape variation but CES preferences.
} 
bution of unit labor requirements, $a_{i j}^{m}$, which we henceforth assume to be non-binding for any industry and country selling to any market? The second-layer, which is non-standard (other than a similar class of heterogeneity in Demidova (2008) and Demidova \& RodríguezClare (2015)), is variation in the Pareto parameter, $k_{i j}$. Variation in this parameter across countries will be crucial for the results, and we will discuss the empirical implications of this parameter shortly.

Although the literature almost generally assumes that Pareto shape is constant across countries within an industry, there is growing evidence that productivity distributions may differ in nuanced ways within industries. Bremus, Buch, Russ \& Schnitzer (2013) document significant differences in firm-size distributions within the banking industry. Further, in the World Bank Exporter Dynamics Database from Cebeci, Fernandes, Freund \& Pierola (2012), there are significant differences in within-HS4-exporter size distributions. Mayer \& Ottaviano (2008) documents exporter-size distributions that deviate from homogeneity across a number of European countries.

To further motivate these more nuanced differences in productivity distributions, I now solve for the average (surviving) firm-level export value from country $j$ to import market $l$ within industry $i$. Precisely, given that a firm from $j$ can serve market $l$ within industry $i$ if $a<\frac{\theta_{i l}}{w_{j} \lambda_{i l} t_{i j l} l}$ I integrate firm-level revenues, $v_{i j l}(a)$, over $\left[0, \frac{\theta_{i l}}{w_{j} \lambda_{i l} t_{i j l}}\right]$ subject to the conditional productivity distribution, $\frac{g_{i j}(a)}{G_{i j}\left(\frac{\theta_{i l}}{w_{j} \lambda_{i l} t_{i j l}}\right)}$ :

$$
\begin{aligned}
E\left[v_{i j l} \mid a<\frac{\theta_{i l}}{w_{j} \lambda_{i l} t_{i j l}}\right] & =\int_{0}^{\frac{\theta_{i l}}{w_{j} \lambda_{i l} t_{i j l}}} \frac{\left(\theta_{i l}^{2}-\left(a w_{j} \lambda_{i l} t_{i j l}\right)^{2}\right)}{4 b_{i l} t_{i j l}} \frac{g_{i j}(a)}{G_{i j}\left(\frac{\theta_{i l}}{w_{j} \lambda_{i l} t_{i j l}}\right)} d a \\
& =\frac{\theta_{i l}^{2}}{2 b_{i l} \lambda_{i l} t_{i j l}\left(k_{i j}+2\right)}
\end{aligned}
$$

In (6), the average surviving firm-level export value does not depend on the upper bound of the Pareto parameter. This is due to average export value being a conditional average (on export status). Thus, when imposing the Pareto distribution, and after controlling for tariffs, average exporter size within an industry does not vary across exporters unless the Pareto parameter $k_{i j}$ differs across $j$. Further, given the monotone relationship between revenues and elasticities, average elasticities do not vary when $k_{i j}$ is homogenous since average firm-

\footnotetext{
${ }^{9}$ For example, see Melitz \& Ottaviano (2008), Hsieh \& Ossa (2015) and Bombardini, Kurz \& Morrow (2012).
} 
level revenues do not vary 10

\section{Long Run Equilibrium Conditions}

With the motivation for the model in-hand, I now turn to the long-run equilibrium conditions that will guide the response to an arbitrary shock. The four conditions, which we detail inorder, are free entry, labor market clearing, trade balance, and a condition I refer to as sectoral optimization (explained below). During the course of analysis, I will show how each condition can be written as a function of observable trade data, endogenous variables, and productivity parameters.

\section{Condition 1 - Free Entry}

Firms enter industry $i$ in country $j$ until expected profits are equal to the fixed cost of entry, $w_{j} F_{i j}$. By imposing the Pareto assumption in (5), expected profits of selling in industry $i$ from $j$ to $l$ are written as:

$$
\bar{\pi}_{i j l}=\frac{\theta_{i l}^{k_{i j}+2}}{2 b_{i l}\left(k_{i j}+2\right)\left(k_{i j}+1\right)\left(a_{i j}^{m}\right)^{k_{i j}} w_{j}^{k_{i j}} \lambda_{i l}^{k_{i j}+1} t_{i j l}^{k_{i j}+1}} .
$$

Aggregating over all available markets, the free entry condition for industry $i$ in country $j$ is written as:

$$
\sum_{l=1}^{M} \frac{\theta_{i l}^{k_{i j}+2}}{2 b_{i l}\left(k_{i j}+2\right)\left(k_{i j}+1\right)\left(a_{i j}^{m}\right)^{k_{i j}} w_{j}^{k_{i j}} \lambda_{i l}^{k_{i j}+1} t_{i j l}^{k_{i j}+1}}=w_{j} F_{i j}
$$

The equilibrium consists of $M \mathrm{x} I$ of these conditions. In (7), the key issue is that if $k_{i j}$ 's are identical across countries and industries and equal to $k$, then the free entry equilibrium consists of a system of equations which are linear in $\lambda_{i l}^{k+1}$ for all $l$. However, when $k_{i j}$ 's vary, the system of free entry conditions will exhibit a different degree of non-linearity for each country-industry pair, which will complicate any analysis of the system of these free entry conditions.

To introduce a novel technique in working with these and other equilibrium conditions in the presence of productivity heterogeneity, note given $N_{i j}$ entrants in industry $i$ in country

\footnotetext{
${ }^{10}$ See Spearot (2013), where I provide evidence the rejects the assumption of constant tariff elasticities when evaluating MFN tariff cuts and imports to the US.
} 
$j$, aggregate trade value from $j$ to $l$ in industry $i$ can be written as follows:

$$
V_{i j l}=\frac{N_{i j} \theta_{i l}^{k_{i j}+2}}{2 b_{i l}\left(k_{i j}+2\right)\left(a_{i j}^{m}\right)^{k_{i j}} w_{j}^{k_{i j}} \lambda_{i l}^{k_{i j}+1} t_{i j l}^{k_{i j}+1}} .
$$

Substituting $V_{i j l}$ into (7), we get:

$$
\sum_{l=1}^{M} \frac{V_{i j l}}{N_{i j} w_{j}\left(k_{i j}+1\right)}=F_{i j}
$$

Clearly, many of the parameters within expected profits are identical to the parameters in trade values. While this does not help pin down the equilibrium values of endogenous variables, this relationship will prove very useful in evaluating equilibrium changes in variables in response to a tariff shock.

\section{Condition 2 - Labor Market Clearing}

Within each market $j, L_{j}$ workers (which also equals the number of consumers in that market) supply one unit of labor, with that labor either devoted to fixed entry requirements or production. Imposing the Pareto distribution, within industry $i$, the expected variable (production) labor requirement per firm for serving market $l$ from $j, l_{i j l}$, is written as:

$$
l_{i j l}=\frac{\theta_{i l}^{k_{j}+2} k_{i j}}{2 b_{i l}\left(k_{i j}+1\right)\left(k_{i j}+2\right)\left(a_{i j}^{m}\right)^{k_{i j}} w_{j}^{k_{i j}+1} \lambda_{i l}^{k_{i j}+1} t_{i j l}^{k_{i j}+1}}
$$

Aggregating over all markets and industries, and adding fixed labor requirements for each industry, we get the labor market clearing condition for country $j$ :

$$
\sum_{i=1}^{I}\left(\left(\sum_{l=1}^{M} \frac{N_{i j} \theta_{i l}^{k_{j}+2} k_{i j}}{2 b_{i l}\left(k_{i j}+1\right)\left(k_{i j}+2\right)\left(a_{i j}^{m}\right)^{k_{j}} w_{j}^{k_{j}+1} \lambda_{i l}^{k_{i j}+1} t_{i j l}^{k_{j}+1}}\right)+N_{i j} F_{i j}\right)=L_{j}
$$

Again, with shape parameter variation, this is a highly non-linear equation in endogenous variables. To simplify, using a similar technique as with free entry conditions, we can impose trade values to get

$$
\sum_{i=1}^{I}\left(\frac{k_{i j}}{\left(k_{i j}+1\right) w_{j}}\left(\sum_{l=1}^{M} V_{i j l}\right)+N_{i j} F_{i j}\right)=L_{j}
$$


The equilibrium consists of $M$ separate labor market conditions. Once again, the nonlinearity of the system of labor market conditions can be "reduced" when writing the system as one of trade values.

\section{Condition 3 - Trade Balance}

In (3), within country $l$, expenditures must equal income:

$$
\sum_{i=1}^{I} \sum_{j=1}^{M} V_{i j l} t_{i j l}=w_{l} L_{l}+T_{l}
$$

Since tariff revenue earned in $l$ is equal to $\sum_{i=1}^{I} \sum_{j=1}^{M} V_{i j l} \tau_{i j l}$, the trade balance condition simplifies to:

$$
\sum_{i=1}^{I} \sum_{j=1}^{M} V_{i j l}=w_{l} L_{l}
$$

Imposing that revenues equal factor payments (from free entry and labor market clearing), we have:

$$
\sum_{i=1}^{I} \sum_{j=1}^{M} V_{i j l}=\sum_{i=1}^{I} \sum_{h=1}^{M} V_{i l h}
$$

The system of trade balance conditions will consist of $M$ equations, but only $M-1$ will be independent. Later, I will detail how we impose a numeraire restriction on the equilibrium.

\section{Condition 4 - Sectoral Optimization}

With the multi-sector model, we have $M \mathrm{x} I$ free entry conditions, $M$ labor market clearing conditions, and $M$ trade balance conditions. However, we have $M \mathrm{x} I N_{i, j}$ 's, $M \mathrm{x} I \lambda_{i l}$ 's, and $M w_{j}$ 's, and thus we need additional equilibrium conditions to fully determine the model (relative to a numeraire). These last conditions obtain from sectoral optimization across $i$ in each country $l$. That is, $\lambda_{i l}$ 's are a function of aggregate utility, sub-utility, and the aggregate Lagrange multiplier, and their values as a function of observables must be consistent with fixed $\beta_{i l}$ 's.

To characterize the sectoral problem, we exploit (again) the Pareto assumption and the definition of sectoral utility. Substituting optimal firm quantities sold to country $l$ into 
equation (2), and imposing the Pareto assumptions for productivity, we can simplify $U_{i, l}$ as:

$$
U_{i, l}=\frac{\lambda_{i l}}{L_{l}} \sum_{j=1}^{M} V_{i j l} t_{i j l}\left(\frac{2 k_{i j}+3}{2 k_{i j}+2}\right)
$$

Sub-utility $U_{i, l}$ has an intuitive formula. Generally, consumers in $l$ will be better off within industry $i$ when expenditures are higher, and this effect is larger when prices within industry $i$ in $l$ are relatively low $\left(\lambda_{i l}\right.$ higher) ${ }^{11}$ However, when there is productivity heterogeneity across countries $j$ that are supplying $l$ in $i$, consumers are better off when they spend income on varieties from countries with a better shape of firms, since they can consume higher quantities with the lower prices offered by a better mix of firms. Hence, expenditures on goods from $j$ in $i$ are weighted by the factor $\left(\frac{2 k_{i j}+3}{2 k_{i j}+2}\right)$, which is decreasing in $k_{i j}$.

To derive the equilibrium conditions that we will use for analysis with data, from the definition of $\lambda_{i l}$, note that utility weights must be linked to utility and multipliers via $\beta_{i l}=$ $\frac{\lambda_{l}}{U_{l}} \frac{U_{i, l}}{\lambda_{i l}}$. Hence, the ratio $\frac{\lambda_{l}}{U_{l}} \frac{U_{i, l}}{\lambda_{i l}}$ is constant. Substituting for $U_{i, l}$, and defining $\delta_{l}=\frac{\lambda_{l}}{U_{l} L_{l}}$, we have

$$
\beta_{i l}=\delta_{l} \sum_{j=1}^{M} V_{i j l} t_{i j l}\left(\frac{2 k_{i j}+3}{2 k_{i j}+2}\right)
$$

Since $\beta_{i l}$ 's are constant, this equation ensures that shape-adjusted expenditures and the utility composite $\delta_{l}$ multiplied together are also constant. Put another way, this ensures that across-sector utility maximization $\left(\delta_{l}\right)$ and within-sector utility maximization $\left(\lambda_{i l}\right)$ are consistent with each other, given the weight $\beta_{i l}$ on industry $i$. There are $M \mathrm{x} I$ of these equations, where we have introduced $M \delta_{l}$ 's to estimate. Later, we will show how $\lambda_{i l}$ 's and $\delta_{l}$ 's can be used to examine overall welfare in response to trade shocks.

For welfare calculations, we will need to solve for $\beta_{i l}$ 's . Substituting each $\beta_{i l}$ into $\sum_{i}^{I} \beta_{i l}=$ 1 , and solving for $\delta_{l}$, we find that (12) simplifies to $\beta_{i l}$ 's being adjusted expenditure shares.

$$
\beta_{i l}=\frac{\sum_{j=1}^{M} V_{i j l} t_{i j l}\left(\frac{2 k_{i j}+3}{2 k_{i j}+2}\right)}{\sum_{i=1}^{I} \sum_{j=1}^{M} V_{i j l} t_{i j l}\left(\frac{2 k_{i j}+3}{2 k_{i j}+2}\right)}
$$

As is well-known, if sub-utility had been homothetic, $\beta_{i l}$ would simply equal the expenditure

\footnotetext{
${ }^{11}$ Later, we will map this utility function into money metric terms to the welfare function appropriate for counterfactuals.
} 
share in $l$ on industry $i$. In the current set-up, $\beta_{i l}$ 's equal adjusted expenditure shares, which have an intuitive relationship with $k_{i j}$ 's. Again, the fraction $\frac{2 k_{i j}+3}{2 k_{i j}+2}$ is decreasing in $k_{i j}$, meaning that consuming from a country-industry with worse firms earns lower utility since a unit of expenditure yields lower real consumption.

\section{Equilibrium}

The long-run equilibrium consists of $M \mathrm{x} I$ free entry conditions (equation 9), $M$ labor market conditions (equation 10), $M$ trade balance conditions (equation 11), and $M \times I$ sectoral optimization conditions (equation 12). These equilibrium conditions pin down $M \times I \lambda_{i, j}$ 's, $M \mathrm{x} I N_{i, j}$ 's, $M \delta_{l}$ 's, and $M w_{j}$ 's (up to required normalizations).

\section{Evaluating Tariff Shocks}

To begin the analysis of tariff shocks, I describe the key "trick" to reducing a complex system of equilibrium conditions to observable data, tariff shocks, and productivity parameters. Specifically, one can write a small change in trade values from $j$ to $l$ in industry $i$ as follows:

$$
d V_{i j l}=V_{i j l}\left(\widehat{N}_{i j}-k_{i j} \widehat{w}_{j}-\left(k_{i j}+1\right) \widehat{\lambda}_{i l}-\left(k_{i j}+1\right) \widehat{t}_{i j l}\right) .
$$

Crucially, $d V_{i j l}$ can be written as a function of initial trade value, $V_{i j l}$, changes in endogenous variables $\widehat{\lambda}_{i l}, \widehat{N}_{i j}$, and $\widehat{w}_{j}$, the tariff shocks, $\widehat{t}_{i j l}$, and productivity shape parameters, $k_{i j}$. Given that all equilibrium conditions are function of $V_{i j l}$ 's, we can greatly reduce the complexity of the problem by working in growth rather than levels.

First, we characterize changes to the free entry condition in (9). Fully differentiating, and imposing the solution for $d V_{i j l}$, we have:

$$
\sum_{l=1}^{M} V_{i j l} \widehat{\lambda}_{i l}+\widehat{w}_{j} \sum_{l=1}^{M} V_{i j l}=-\sum_{l=1}^{M} V_{i j l} \widehat{t}_{i j l}
$$

Next, fully differentiating the labor market clearing condition for country $j$ in $(10)$, and imposing the solution for $d V_{i j l}$, we get:

$$
\sum_{i=1}^{I} \sum_{l=1}^{M} V_{i j l}\left(-\widehat{N}_{i j}+\left(k_{i j}+1\right) \widehat{\lambda}_{i l}+\left(k_{i j}+1\right) \widehat{w}_{j}\right)=-\sum_{i=1}^{I} \sum_{l=1}^{M} V_{i j l}\left(k_{i j}+1\right) \widehat{t}_{i j l}
$$


Imposing the fully differentiated free entry for each industry within this fully differentiated labor market clearing condition, we get the following simplified expression for changes to entry across countries and industries:

$$
\sum_{i=1}^{I}\left(\widehat{N}_{i j} \sum_{l=1}^{M} V_{i j l}\right)=0
$$

Note that in a one-sector framework, this result implies that entry is invariant to shocks. In a multi-sector context, while entry is not invariant, entry weighted by trade values is equal to zero, and hence, any entry in one industry must be balanced by exit in at least one other.

Next, differentiating trade balance in (11), we have:

$$
\begin{aligned}
-\sum_{i=1}^{I} \sum_{j=1}^{M} \widehat{N}_{i j} V_{i j l}+\sum_{i=1}^{I} \widehat{\lambda}_{i l} \sum_{j=1}^{M}\left(k_{i j}+1\right) V_{i j l} & \\
+\sum_{j=1}^{M} \widehat{w}_{j} \sum_{i=1}^{I} k_{i j} V_{i j l}+\sum_{i=1}^{I} \sum_{j=1}^{M}\left(k_{i j}+1\right) V_{j l} \widehat{t}_{j l} & =-\sum_{i=1}^{I} \sum_{h=1}^{M} \widehat{N}_{i l} V_{i l h}+\sum_{i=1}^{I} \sum_{h=1}^{M} \widehat{\lambda}_{i h}\left(k_{i l}+1\right) V_{i l h} \\
& +\widehat{w}_{l} \sum_{i=1}^{I} \sum_{h=1}^{M} k_{i l} V_{i l h}+\sum_{i=1}^{I} \sum_{h=1}^{M}\left(k_{i l}+1\right) V_{i l h} \widehat{t}_{i l h}
\end{aligned}
$$

As there are only $M-1$ independent trade balance conditions, we must adopt a numeraire assumption. While there are a number of ways to do this, we follow Costinot \& RodríguezClare (2013) and require that world income equal unity: $\sum_{j=1}^{M} w_{j} L_{j}=1$. In response to any shock, this requires that:

$$
\sum_{j=1}^{M} \widehat{w}_{j} \sum_{i=1}^{I} \sum_{l=1}^{M} V_{i j l}=0
$$

Finally, we must solve for changes to the $M \mathrm{x} I$ sectoral optimization conditions, defined in equation (12). Again writing endogenous variables in percent changes, we can fully differentiate the sectoral optimization condition to get:

$$
\begin{array}{r}
-\widehat{\delta}_{l} \sum_{j=1}^{M} V_{i j l} t_{i j l}\left(\frac{2 k_{i j}+3}{2 k_{i j}+2}\right)-\sum_{j=1}^{M} V_{i j l} t_{i j l}\left(\frac{2 k_{i j}+3}{2 k_{i j}+2}\right) \widehat{N}_{i j}+\widehat{\lambda}_{i l} \sum_{j=1}^{M} V_{i j l} t_{i j l}\left(\frac{2 k_{i j}+3}{2}\right) \\
+\sum_{j=1}^{M} V_{i j l} t_{i j l}\left(\frac{2 k_{i j}+3}{2 k_{i j}+2}\right) k_{i j} \widehat{w}_{j}=-\sum_{j=1}^{M} V_{i j l} t_{i j l}\left(\frac{2 k_{i j}+3}{2 k_{i j}+2}\right) k_{i j} \widehat{t}_{i j l}
\end{array}
$$


To summarize, in (14), (15), (16), (17) and (18), which guide the effects of any tariff shock, there are three types of terms. The first are changes to endogenous variables, which are $M \mathrm{x} I \lambda_{i, j}$ 's, $M \mathrm{x} I N_{i, j}$ 's, $M \delta_{l}$ 's, and $M w_{j}$ 's (restricted by the numeraire). The remaining two types of variables in (14), (15), (16), (17) and (18) are productivity shape parameters, which must be estimated, and then finally, observable data (trade values, tariffs, and tariff shocks).

The solution characterized above can be arranged in matrix form, which facilitates straightforward counterfactual estimation. As the solution is fairly large, I relegate this to Appendix A, outlining the solution for both the one sector and multi-sector models. For both cases, the key result is summarized in the following Proposition.

Proposition 1 If, after normalizing world income to unity, the Jacobian matrix of equilibrium conditions is full rank, the effects of a tariff shock on endogenous variables are a unique function of initial bilateral trade data and tariffs, tariff cuts, and productivity shape parameters.

The results in Proposition 1 indicate that all that is needed to evaluate the effects of an arbitrary shock on endogenous variables is a matrix of trade data, tariff data, and productivity shape parameters. However, before moving to the empirics, I outline the welfare and performance metrics that will be used to evaluate these tariff shocks.

\section{E Metrics for Welfare Evaluation}

The welfare effects of tariff shocks will be the primary focus of the empirical section. Using the formula in $U_{i, l}$, and writing adjusted expenditure shares as derived in (13), percent changes in total utility can be written as:

$$
\widehat{U}_{l}=\sum_{i=1}^{I} \underbrace{\frac{\sum_{j=1}^{M} V_{i j l} t_{i j l}\left(\frac{2 k_{i j}+3}{2 k_{i j}+2}\right)}{\sum_{f=1}^{I} \sum_{j=1}^{M} V_{f j l} t_{f j l}\left(\frac{2 k_{f j}+3}{2 k_{f j}+2}\right)}}_{\beta_{i l}}\left(\widehat{\lambda}_{i l}-\widehat{\delta}_{l}\right)
$$

As this metric is generated from non-homothetic preferences, we must scale $\widehat{U}_{l}$ into money metric terms using equivalent variation to measure appropriate changes in welfare. In the online appendix, I show that equivalent variation, $\widehat{E V}_{l}$, is linked to utility changes $\widehat{U}_{l}$ proportionally, with this proportion being a ratio of shape adjusted expenditures and actual 
expenditures.

$$
\widehat{E V}_{l}=\frac{\sum_{f=1}^{I} \sum_{j=1}^{M} V_{f j l} t_{f j l}\left(\frac{2 k_{f j}+3}{2 k_{f j}+2}\right)}{\sum_{f=1}^{I} \sum_{j=1}^{M} V_{f j l} t_{f j l}} \widehat{U}_{l}
$$

Since $\frac{2 k_{f j}+3}{2 k_{f j}+2}$ is generally above one, equivalent variation will be larger in magnitude relative to percent changes in $\widehat{U}_{l}$.

Two secondary measures will be used to help build intuition for the mechanisms behind welfare effects. First, we will focus on the industry-level $\lambda_{i l}$. Since this measure scales the entire inverse demand function, we interpret changes to $\lambda_{i l}$ as changes to product market competition. Hence, product market competition rises when $\lambda_{i l}$ rises. Second, we will evaluate changes in overall competition by focusing on the unit-labor-requirement-cutoff for selling domestically in industry $i$ in country $j$. Precisely, since domestic firms in $j$ can produce for their home market when $\theta_{i j}>a w_{j} \lambda_{i j}$, we define the highest-cost firm that is on the margin between operating and exiting, $a_{i j} \equiv \frac{\theta_{i j}}{w_{j} \lambda_{i j}}$. Hence, competition for factors and consumers is more fierce when $w_{j} \lambda_{i j}$ rises.

\section{F Comparison to CES}

Given the non-constant aggregate tariff elasticities that are at the heart of the above framework, existing results in Arkolakis, Costinot \& Rodríguez-Clare (2011), Arkolakis, Costinot, Donaldson \& Rodríguez-Clare (2012), Costinot \& Rodríguez-Clare (2013) do not directly apply. In the online technical appendix, I prove the following Proposition that characterizes equivalence of the variable shape framework with linear demand (as derived above) with a variable shape framework with CES demand.

Proposition 2 Consider a CES model with substitution elasticity $\sigma_{i}$ within industry $i$, and $k_{i j}$ as the shape parameter for industry $i$ and country $j$. If $\sigma_{i}=\sigma$ for all $i$ and $k_{i j}=k$ for all $i$ and $j$, the CES model can be re-scaled such that the equilibrium effects of shocks are quantitatively identical to the linear case, and welfare effects are qualitatively identical. Otherwise, the equilibrium and welfare effects are not identical.

Despite the knife's edge condition required for equivalence, there are strikingly common features across the models. For both models, free entry, trade balance, and labor market clearing can all be defined in terms of a partial tariff elasticity, which in the linear case is $k_{i j}+1$ and the CES case is $k_{i j} \frac{\sigma_{i}}{\sigma_{i}-1}$, along with rescaled endogenous variables and trade 
values. Hence, these three conditions are effectively identical. However, when shape varies, expenditure shares are not constant as they are in CES and therefore the equilibrium and response to shocks may differ.

In terms of welfare, the response to any shock in the CES model is characterized by:

$$
\widehat{E V}_{l}^{c e s}=\widehat{U}_{l}^{c e s}=\sum_{i=1}^{I} \beta_{i l} \frac{\sigma_{i}}{\sigma_{i}-1}\left(\widehat{\lambda}_{i l}^{c e s}-\widehat{\delta}_{l}^{c e s}\right)
$$

where $\widehat{\lambda}_{i l}^{\text {ces }}$ and $\widehat{\delta}_{l}^{\text {ces }}$ are changes to endogenous parameters in the CES model (and are defined analogously to the linear case), and $\beta_{i l}$ will simply equal expenditure shares. Welfare effects are generally different since $\frac{\sigma_{i}}{\sigma_{i}-1}$ scales changes to sub-utility in each sector, along with the differences in sectoral optimization. However, under Proposition 2, welfare effects are qualitatively identical when $k_{i j}$ and $\sigma_{i}$ do not vary since $\widehat{\lambda}_{i l}^{\text {ces }}$ and $\widehat{\delta}_{l}^{\text {ces }}$ are identical to the linear case and $\frac{\sigma}{\sigma-1}$ does not affect the sign of the summation in 21 .

\section{Empirics}

In this section, I develop procedures to estimate productivity shape using tariff variation subsequent to the Uruguay Round tariff negotiations. These shape estimates will facilitate tariff counterfactuals that will be presented in the following section.

\section{Empirical Specification}

To begin, recall the equation for trade value as described in equation (8):

$$
V_{i j l}=\frac{N_{i j} \theta_{i l}^{k_{i j}+2}}{2 b_{i l}\left(k_{i j}+2\right)\left(a_{i j}^{m}\right)^{k_{i j}} w_{j}^{k_{i j}} \lambda_{i l}^{k_{i j}+1} \cdot t_{i j l}^{k_{i j}+1}}
$$

Adding in a distance component $d_{i j l}$, which may be made up of a number of factors, and the cost of which is assessed CIF for purposes of duty calculations, producer trade values are written as:

$$
V_{i j l}=\frac{N_{i j} \theta_{i l}^{k_{i j}+2}}{2 b_{i l}\left(k_{i j}+2\right)\left(a_{i j}^{m}\right)^{k_{i j}} d_{i j l}^{k_{i j}} w_{j}^{k_{i j}} \lambda_{i l}^{k_{i j}+1} t_{i j l}^{k_{i j}+1}}
$$


From here, we can take two routes toward estimating shape parameters. We could implement a typical gravity estimator, whether by OLS or PPML, to estimate $V_{i j l}$ as a function of fixed and interactive factors, tariffs, and distances. Doing so in an unbiased fashion requires a correct specification of the distance factor, $d_{i j l}$. Given that distance can be a function of geographic distance, cultural distance, and other exporter and importer specific differences (port delays, for example), a rich framework would be required to properly account for all the factors in $V_{i j l}$. Given the added non-linearities related to heterogeneous $k_{i j}$ 's, we will save on parameters and estimate the gravity specification in growth rather than in levels.

Precisely, assuming that productivity shape and distance do not change over the period, but allowing for all other factors to change, we can write log changes of trade from $j$ to $l$ in industry $i$ as

$$
\Delta \log V_{i j l}=\left(k_{i j}+1\right) \alpha_{i l}-\left(k_{i j}+1\right) \Delta \log \left(t_{i j l}\right)+D_{i j}^{x}+D_{i l}^{m}+\varepsilon_{i j l}
$$

where $\left.\alpha_{i l}=\Delta \log \left(\theta_{i l}\right)-\Delta \log \left(\lambda_{i l}\right), D_{i j}^{x}=\Delta \log \left(N_{i j}\right)\right)-k_{j} \Delta \log \left(a_{j}^{m}\right)-k_{j} \Delta \log \left(w_{j}\right)$, and $D_{i l}^{m}=\Delta \log \left(\theta_{i l}\right)-\Delta \log \left(b_{i l}\right)$. Here, note that we are absorbing a number of shocks that vary at the importer-industry and exporter-industry levels. Though not explicitly modeled, this could include strategic port-delays or other non-tariff and technical barriers to trade that may vary by country and industry. Thus, this specification is very general and can be used to estimate shape parameters as embodied in the tariff elasticities.

However, complicating this specification is the interaction between two parameters to estimate, $\left(k_{i j}+1\right)$ and $\alpha_{i l}$, which requires a variety of exclusion restrictions to estimate all $k_{i j}$ 's. I now will discuss maximum likelihood procedure and identifying restrictions on the data to estimate the shape parameters.

\section{Estimation}

Though uncommon in the trade literature, the class of specification in 22 is commonly referred to as a "Bi-linear Model" in demography and survival analysis (eg. Brouhns, Denuit \& Vermunt (2002)). The interaction of parameters, and issues surrounding this interaction, requires discussion. Roughly speaking, the theoretical identification requirements for $k_{i j}$ 's are the following:

1. Absent any subtle co-linearity issues, we must drop either one each of $D_{i l}$ and $D_{i j}$, or one $\alpha_{i l}$ and either one of $D_{i l}$ or $D_{i j}$. 


\section{Sufficient variation in $\Delta \log \left(t_{i j l}\right)$ across $j$ within each $l$.}

Condition (1) is essentially the exclusion restriction that one normal requires with fixedeffects OLS models, but extended for the multiplicative effect within $\left(k_{i j}+1\right) \alpha_{i l}$. One way to think of this condition is taking $k_{i j}$ 's as "data", and choosing the excluded groups in a way similar to a difference-in-difference specification. As for taking $k_{i j}$ 's as data, (2) accomplishes this. For example, with appropriately normalized $\alpha_{i l}$ 's (which is required even without using tariffs to estimate the $k_{i j}$ 's), one can estimate a response across $j$ within $l$ when tariffs vary at the bilateral level (as they do quite a bit). In Appendix E (online), I show theoretically how (22), lacking bilateral tariff variation within $l$, implies that $k_{i j}$ can only be identified relative to its industry $i$ mean. However, when there is even minimal variation in $\Delta \log \left(t_{i j l}\right)$ within $l$, the estimator (set-up as an iterative fixed point procedure) finds the correct parameter values with high accuracy.

Since the specification is non-linear, and includes a relatively large number of parameters to estimate, I use the following procedure for estimation of (22):

1. For each industry $i$, estimate (22) using maximum likelihood (ML) restricting that $\alpha_{i l}=0$ for all $l$. (thereby eliminating the non-linearity within the specification)

2. Collect values of $k_{i j}, D_{i j}^{x}$, and $D_{i l}^{m}$ from the linear ML and use as starting values for the full estimation of 22 .

3. Set starting values of $\alpha_{i l}$ 's at zero, so that the procedure starts at the linear ML optimum.

4. Estimate the non-linear ML using the same exclusions on $D_{j}^{x}$, and $D_{l}^{m}$ from the restricted model, and excluding one $\alpha_{i l}$ for identification of relative $\alpha_{i l}$ 's.

5. Sample residuals by Wild Bootstrap as in Davidson \& Flachaire (2008), and repeat 1000 times to calculate bootstrap shape estimates and standard errors ${ }^{12}$

For interested readers, in Appendix D, I have provided additional details on this estimation procedure, including some Monte Carlo examples illustrating when the procedure succeeds in identifying the underlying parameters and when it fails. The crucial result from this appendix is that given the first fours steps from above, using random data for each simulation, the

\footnotetext{
${ }^{12}$ The Wild Bootstrap is used since it is a simple residual-resampling technique to construct heteroskedasticity robust standard errors.
} 
estimation procedure successfully identifies the true $k_{j}$ 's within every simulation exercise, but only when there is bilateral variation in tariffs.

The final piece of the estimation routine is constraining the space over which we seek a solution. For shape parameters, we will constrain the procedure and allow for $k_{j} \in[0,20]$. For the fixed effects, $D_{j}^{x}$ 's and $D_{l}^{m}$ 's, since these are log changes of unobserved variables, we restrict their support to be between -5 and 5 . These restrictions are imposed for two reasons. First, the restrictions on $k$ 's are meant to impose a proper PDF. The latter restrictions are meant to prevent the procedure from focusing too much on outlier growth rates, which may be extremely sensitive to noisy trade data.

\section{Data}

The data from this project come from two widely used sources. Tariffs and trade data used for estimation of shape parameters come from the TRAINS database. The full trade matrix for purpose of counterfactuals comes from the 6th version of the Global Trade Analysis Project (GTAP). The GTAP data is organized by 57 sectors, and includes 87 countries some of which aggregated regions of very small countries. The benefit of the GTAP database is that it is internally consistent, which is appropriate for the counterfactual analysis of wages and other variables in this paper. The downside of GTAP is that it is not a panel, which is why TRAINS is used to estimate 22, and to obtain tariff data for counterfactuals.

The TRAINS data reports tariffs using the GTAP sectoral and country definitions, and hence, we will estimate shape parameters by GTAP industries and countries. To estimate shape parameters, we use variation in applied tariffs that occurred during the period subsequent to Uruguay Round Tariff negotiations. When there are missing applied tariff values, we assign the average MFN tariff applied by importer $l$ in industry $i$ for each year. Tariff cuts were negotiated over the period 1990-1994, with the majority of cuts occurring between 1994 and 2000, though some cuts continued until 2004 13 Regional agreements, such as NAFTA, were also implemented over this period and are included in the measured tariff cuts. With this timing in mind, for trade from $j$ to $l$ in industry $i$, we assign initial tariff values as the maximum reported tariff over the period 1990-1994. The final tariff we assign is the minimum reported tariff over the period 2000-2004.

Trade values from $j$ to $l$ in industry $i$ are subject to similar issues with poor reporting, especially prior to 1994. So, to construct the pre-period trade value from $j$ to $l$ in industry $i$,

\footnotetext{
${ }^{13}$ In the US $80 \%$ a large portion of cuts were competed by 2000 , with some additional movement until 2004. See Spearot (2013).
} 
I take the average reported trade value between 1993 and 1995. If there are missing values, they are not included in the average. For the post period, I use 1999-2001.14

To provide some descriptive evidence regarding the validity of using tariffs to identify shape estimates, Figure 1 presents two panels, the first reporting within origin-destinationindustry tariff changes from 1990 to 2004, and average log trade growth relative to 1994 for origin-destination-industries depending on whether they received an above median or below median tariff cut. In the upper-panel, we see that within origin-destination-industry groups, tariffs fell by around 5 percentage points between 1990-2004. This is substantial relative to the sample average tariff of $9 \%$ in 2000 . Further, though noisy (due to many countries only reporting one year during this period), there is little trend in tariffs between 1990 and 1994. Afterward, tariffs fall sharply. In the bottom panel, it is clear that prior to 1994, origindestination-industries that received an above median tariff cut were not growing differently than groups that did not receive a tariff cut. After 1994, the groups diverge with those receiving a large tariff cut experiencing greater trade growth relative to 1994. Overall, it appears from Figure 1 that tariff variation was substantial, and that accelerations in trade growth followed the groups with larger tariff cuts.

\section{Shape Estimates}

The results from the estimation of productivity shape are presented in Tables 1 and 2 . To begin, we discuss the industry-level shape estimates that are feasibly estimated with tariff data. Of the 57 GTAP sectors, 18 are classified as non-tradables or services so tariffs are not reported and thus shape cannot be estimated. Of the 39 industries that do have an estimated shape parameter for at least one country, the results are presented in Table 1. The first two columns report the industry identifier, and the next three columns report the mean, median and standard deviation for each industry. The last column "Significant Shape Var.", reports whether we can reject the restriction of shape homogeneity within each industry using a likelihood ratio test. Indeed, for all industries shape homogeneity is rejected at a high level.

\footnotetext{
${ }^{14}$ Note that both trade and tariffs may include both horizontal final goods trade as well as vertical trade. As the model is one of only horizontal trade, I have engaged in a number of robustness checks to evaluate the effect of intermediates on the estimation of shape parameters. Available upon request, I have calculated within each GTAP sector the share of HS6 products that include "parts" or other intermediate designations in sub-HS6 categories. Information on these linkages are taken from Schott (2004). Parts designations are only present in 15 GTAP sectors, and mostly involve a small share of HS6 products that are identified as parts or other intermediates. I have re-run all estimation after removing these HS6 products with any parts share, and the corresponding shape estimates are highly correlated with the original estimates. I plan to address intermediate trade more rigorously in future work.
} 
Figure 1: Tariff changes and Trade Growth
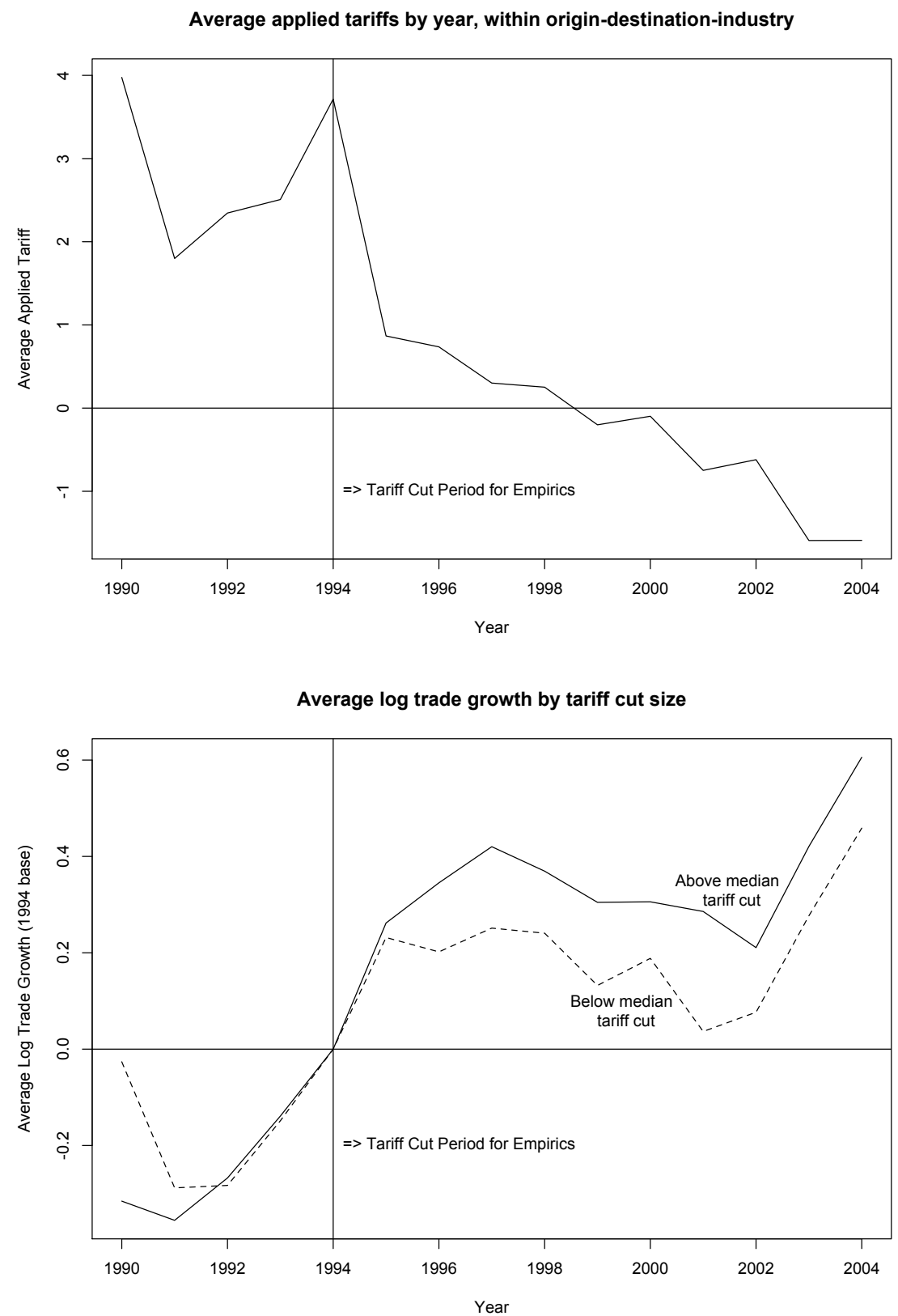

Notes: The upper panel of this figure reports average tariff changes within origin-destination-industry groups over 1990-2004. The bottom panel reports average log trade growth (1994 base) for origin-destinationindustry groups depending on whether the group received an above median or below median tariff cut. Source: Author's calculations using data from TRAINS. 
Looking across industries, we see that there is significant variation in average industry shape estimates. For example, in the Paddy Rice industry (GTAP 1), the average shape estimate is 6.63. In contrast, in the Metal Products industry (GTAP 37), the average shape is 3.11. If these two industries were compared using a similar demand function, this would imply that surviving average firm size in metal products is much larger than in the Paddy Rice industry.

Now turning attention to the averages of shape estimates by country, we report countrylevel averages in Table 2. Here, we report the country average shape estimate across all industries, $\bar{k}_{j}$, and the average deviation of each $k_{i j}$ from the industry mean divided by the bootstrap standard error ("AvgT"). The main takeaway from Table 2 is that when looking at the broad averages across countries, there appears to be significant variation in shape. Countries such as the US and Germany are productivity leaders, with the typical shape estimate more than one standard deviation below each industry mean. A number of developing countries (Bangladesh, Malawi and Mozambique) have the worst shape of firms, which are typically above each industry mean.

\section{Shape Estimates and External Validity}

Given the non-standard approach of inferring productivity distributions from trade data, I now compare the estimated shape parameters to external measures of firm characteristics. Complicating this assessment is that there exist no comprehensive firm-level datasets that are harmonized internationally for a large set of countries. However, for a subset of countries, there are two datasets that will prove useful for external validation of the shape estimates.

The first is the World Management Survey (WMS) in Bloom \& Van Reenen (2006), which is a randomized survey of businesses and their management practices. The benefits of using the WMS for external validity is that the survey methodology was consistently applied across many countries and industries. While not explicitly measuring firm-size, it is available for 30 matching countries in my sample and measures management techniques that have been validated in an experimental setting as meaningful factors for productivity and profitability (see Bloom, Eifert, Mahajan, McKenzie \& Roberts (2013)) ${ }^{15}$ To evaluate the association between shape estimates and management scores, I first construct a normalized shape estimate for each country and industry by taking log differences of $\widehat{k}_{i j}$ relative to the industry average. For the management survey, I first match SIC industries (which are

\footnotetext{
${ }^{15}$ I am deeply grateful to the World Management Survey team for access to the newest dataset with industry codes.
} 
used in the WMS) to GTAP industries, and then take the log average management score for each country-industry group and de-mean by the log of the industry average. The raw correlation between these log de-meaned shape and management scores is -0.296 . To make clear this relationship in the data, I average these log de-meaned values by country, and present the results in Figure 2. Here, there is a clear negative association between shape and management scores, which makes sense since lower shape and higher management scores both imply better firms.

As a second test of external validity, I utilize firm-level trade statistics from the Exporter Dynamics Database (EDD) as collected in Cebeci, Fernandes, Freund \& Pierola (2012). Specifically, the EDD makes available the average and standard deviation of firm-level trade value for about 40 countries, mostly less or least developed, under a wide variety of aggregation schemes. For the present exercise, I use the exporter-importer-year extract to facilitate looking at the exporter size distribution within importer-year groups ${ }^{16}$ I use the same log de-meaned shape estimates to summarize average country shape. To measure average firm size, I take the exporter-importer-year log average firm-level export value, and then subtract the log of the mean importer-year average firm-level export value. Then, I take the average of these firm-size normalizations by country, and plot them against average shape estimates by country. Again, there is a negative association between normalized shape and normalized firm-size. Hence, using two independently collected datasets, the shape estimates from the paper match features of firm-size distributions in a way indicated by the model.

In online Appendix F, I continue the study of external validity by associating shape estimates with development, country size, and within importer-industry trade values. Again, we find intuitive associations between shape and these values. A better shape of firms is associated with more developed and larger countries, as well as larger trade flows within importer-industry groups. I find little relationship between capital-labor ratios and shape, suggesting that production technology and capacity constraints are not driving the estimation of shape.

\footnotetext{
${ }^{16}$ Ideally I would look at the exporter distribution within importer-industry-year groups but this level of aggregation is not supplied, presumably since it might implicitly identify a relatively few exporting firms in small countries.
} 
Figure 2: External Validity of Shape Parameters

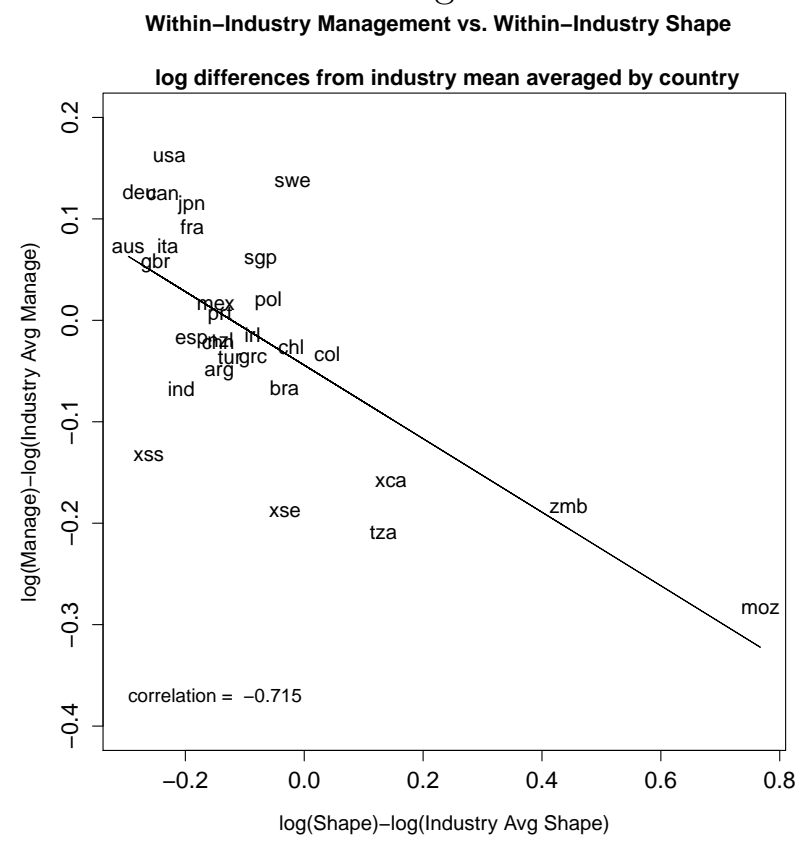

Within-Market Exporter Size vs. Within Market Shape

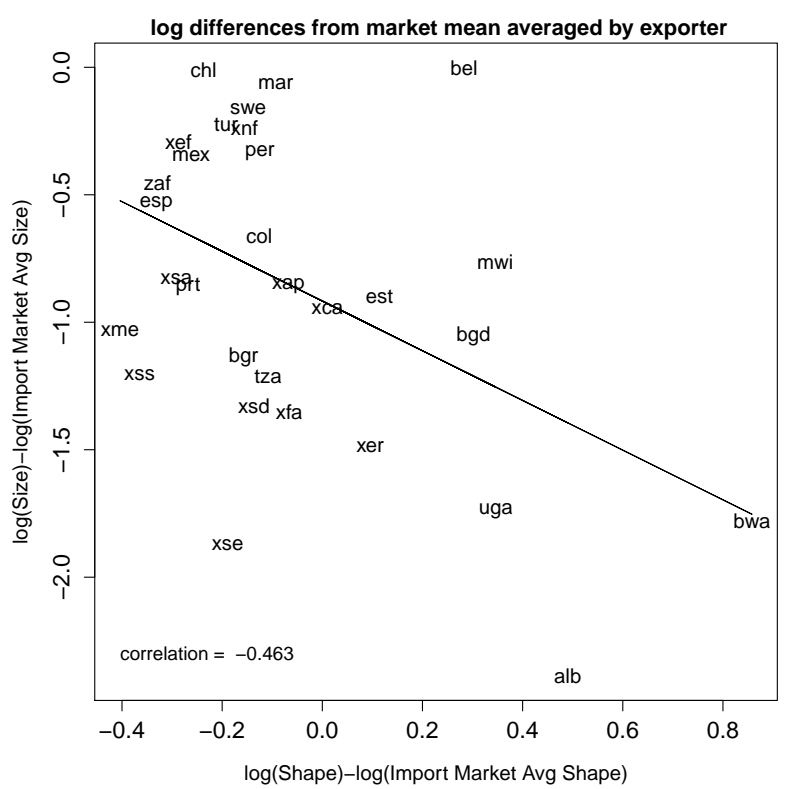

Notes: The left panel illustrates the association between average normalized management scores (vertical axis) and average normalized shape parameters by country. The right panel illustrates the association between average normalized within-importer-year firm size (vertical axis) and average normalized shape parameters by country. Source: Author's calculations using shape estimates and data from the World Bank Exporter Dynamics Dataset and the World Management Survey. 


\section{Tariff Counterfactuals}

I now use the shape estimates in conjunction with trade data and tariff cuts to run a number of counterfactual experiments. As motivated in the introduction, the effects of a large tariff shock are difficult to measure for a number of reasons. First, given the large number of equilibrium conditions, evaluating the effects of a large tariff shock absent assumptions over parameters is fairly difficult. Further when there is any heterogeneity in average exporter elasticities - in my case through the shape of the productivity distribution - the large number of equilibrium conditions is highly non-linear and intractable to solve. Using the techniques in this paper, I can evaluate any arbitrary policy shock after adopting an appropriate normalization by inverting a matrix of built from trade data and productivity shape parameters.

To construct the bilateral trade matrix for each counterfactual, I use the GTAP version 6 matrix, which is measured and internally consistent for the year 2001. Tariff data is the same as used for the estimation of shape parameters in section three. For country-industry pairs without an estimated shape parameter, I assign the average of shape parameters for that industry. Finally, the GTAP expenditure matrix is used to construct shape-adjusted expenditures (since policies other than tariffs may drive a wedge between producer revenues and consumer expenditures).

\section{A Tariff Shocks and the Role of Shape Variation}

To begin, I study the effect of shape variation on the long-run effects of tariff shocks using unilateral policy changes by the US. Though multilateral changes in tariffs are the predominant focus within current rounds of trade negotiations, unilateral tariff changes are an important input for the tariff-based prisoner's dilemma that trade agreements are designed to alleviate (Ossa (2011), Bagwell \& Staiger (2012), and Bagwell \& Staiger (2015)). Traditionally, to examine unilateral liberalization, we do so in a one-sector model with two countries. In this standard set-up, there are no trade diversion effects, and if there is no productivity heterogeneity across suppliers, the welfare effects are relatively easy to characterize.

In contrast, my model includes countries and industries with potentially significant heterogeneity across and within industries, so to begin we will examine a $10 \%$ increase in import tariffs by the US (from post-2000 levels) in all 57 GTAP industries ${ }^{17}$ We address this coun-

\footnotetext{
${ }^{17}$ Note that if an industry is non-traded, and therefore reports only domestic trade with itself in the GTAP matrix, the direct effects of the tariff shock on that industry will be zero. Consequently, any effects will be
} 
terfactual in three different ways, and the results from doing so are presented in Table 3. In the first column, we present the results from the aggregate model in (25) assuming that productivity shape is common across all countries. In this case, the only factor guiding the effects of the unilateral tariff shock is the bilateral trade matrix (and functions thereof). In the second column, we use the 57 sector model in (27), assuming that productivity shape varies by industry but is common across countries within each industry. Finally, in the third column, we allow for across and within industry variation in shape for all sectors and countries 18

First, focus on the results of each counterfactual for the US. As is supported by more compact models, a unilateral increase in tariffs can yield a welfare gain for a large country that is also collecting tariff revenue. Indeed, for all three counterfactuals, the US enjoys higher welfare from increasing its own tariffs by $10 \%$. These effects are quite modest, as the US is a large country that (mostly) trades with itself. As for the effects on other countries, the results vary, though importantly, productivity shape variation can have a qualitative effect on changes to welfare. To decompose this effect, comparing columns one and two allows for across-industry shape differences, but not within-industry differences. Indeed, column two adopts assumptions most similar to the existing literature in Caliendo \& Parro (2015), Costinot \& Rodríguez-Clare (2013), and Ossa (2014). Here, we find that the welfare effects of a unilateral increase in US tariffs change qualitatively for $21 \%$ of countries in the sample. When adding within-sector shape heterogeneity, comparing column two and column three, we find that there is a qualitative change in welfare effects for $4 \%$ of countries in the sample. Thus, within-sector shape variation matters qualitatively for some countries in the sample. In terms of quantitative differences, for $66 \%$ of countries in the sample, including within-industry shape variation mitigates the negative effect of higher US tariffs. Though modest, these $66 \%$ of countries tend to have a lower value of shape (0.4 lower, on average), which suggests that higher tariffs may disproportionately hurt countries with a poor shape of firms 19

through general equilibrium changes to wages and entry.

${ }^{18}$ Note that in comparing these columns, the results should be understood to be partial effects of shape on the equilibrium, since I am not accounting for the effects of shape on equilibrium trade values. Studying the full effect of shape harmonization is left for future work.

${ }^{19}$ This is consistent with micro evidence in Spearot (2013), which evaluates the disparate effects of US tariff cuts during the Uruguay Round 


\section{B Unilateral Tariff Liberalization and Misallocation}

Next, I study the unilateral effects of tariffs in two ways to highlight potential inefficiency, or misallocation, in tariffs set by each country. As standard trade theory suggests that countries can optimally set non-zero tariffs if the incidence of the tariff is sufficiently placed on export suppliers, we would expect that unilaterally raising tariffs from current levels (which have been lowered over time by trade agreements) would have a positive welfare effect and lowering them would have a negative welfare effect. This intuition may fail if tariffs are inefficiently high, or tariffs are set discriminately across countries and industries in a way that is welfare reducing.

To study these issues, for each country, I run two unilateral counterfactuals: a $10 \%$ increase in all tariffs ("10\% $\Uparrow "$ ), and a removal of post-2000 tariffs ("All $\Downarrow ")$. To be clear, these two counterfactuals compare a non-discriminatory tariff increase ("10\% $\Uparrow ")$, to a tariff reduction that discriminates based on year 2000 tariffs ("All $\Downarrow "$ ). The results from both counterfactuals are presented in Table 4. The first two columns for each country measure the welfare effects of these two counterfactuals, and the third column summarizes changes in the critical cost cut-off when each country raises all tariffs by $10 \%$. First, focus on the results for the US, where we find that the US gains from increasing all tariffs by $10 \%$ from year 2000 levels. However, when removing observed tariffs, we also find that the US gains. Though surprising, this can occur in two ways. Since industries, and countries within industries, can vary in productivity shape, they can also vary in average demand elasticity. In terms of consumer welfare, when demand elasticity varies, the optimal tax scheme is to subsidize high price varieties and tax low cost varieties, thereby evening-out consumption within the variety set. Therefore, if tariffs are set optimally higher on low elasticity suppliers, then removing them should reduce welfare. On the other hand, if welfare goes up when tariffs cuts are skewed toward low elasticity suppliers, this suggests that any tariff discrimination was inefficient relative to free trade. Indeed, since discrimination in the WTO tends to be all or nothing free-trade through bilateral agreements or GSP programs, the latter is exactly what I find. While there are no subsidies in the results in Table 4, remaining tariff reductions by the US are skewed toward lower values of $k$ (raw correlation of 0.13 between shape estimates and log tariff changes). Hence, the pre-tariff cut misallocation is such that there is too much discrimination, and the lack of discrimination after all US tariffs are removed is evidently a better outcome for the US relative to pre-tariff cut discrimination.

Turning to other countries, like the US, $87 \%$ of countries benefit from a $10 \%$ increase

in their own tariffs. However, unlike the US, $77 \%$ of countries lose when they reduce all 
observed tariffs to zero. Of those countries that can gain by reducing their observed tariffs to zero, India, Japan, Korea, US and Vietnam stand out as notable examples. This highlights an interesting feature of the current state of tariffs, where some countries that may be negotiating within larger agreements would already gain by acting unilaterally.

Finally, in column three of Table 4. I study the impact of unilateral tariff shocks on competition. Specifically, I report the share of industries in each country that experience an increase in overall competition in response a $10 \%$ increase in all tariffs, which manifests in a reduction in the critical cost cut-off necessary for domestic production. This counterfactual is of particular interest since it relates most closely with theoretical results in one-industry, two-country models in Venables (1985), Melitz (2003), and Demidova \& Rodríguez-Clare (2015). As is supported by most theoretical models with a labor market, higher tariffs reduce competition far more than it increases competition in the domestic market. However, in some small and developing countries, higher tariffs increase competition in a non-trivial share of industries. Madagascar and Mozambique see an increase in competition in 19\% and $25 \%$ of industries, respectively, and Malaysia sees an increase in competition in $53 \%$ of industries. Overall, while higher tariffs do tend to decrease overall competition for most countries, there are some exceptions which are important to consider in future models of multilateral trade policy.

\section{Multilateral Tariff Shocks and Trade Agreements}

We now turn to larger sets of tariff reductions on a multilateral basis. To begin, I run a counterfactual in which all countries raise their tariffs by $10 \%$. The results from this counterfactual, with and without within-industry shape heterogeneity, are presented in Table 5. With shape homogeneity within industries, $71.2 \%$ of countries are worse off. When allowing for shape heterogeneity within industries, $65.5 \%$ of countries lose from a common increase in tariffs. In some cases, these effects are predicted to be extremely large. Considering again the role of shape variation in guiding these welfare effects, we find that the negative effects of a $10 \%$ increase in tariffs by all countries appear to be mitigated for $62 \%$ of countries when allowing for shape variation. However, there are exceptions, where for example, Indonesia suffers a $2.50 \%$ welfare loss when shape is common within industries and a $2.92 \%$ welfare loss when shape is heterogeneous.

As a benchmark for evaluating the welfare effects of tariff shocks vis-a-vis development, I compare the GDP per capita of those that lose from this shock (with shape heterogeneity), 
and those that prefer the setting of higher tariffs. I find that those countries that lose from the multilateral 10\% tariff cut (average GDPPC $=\$ 10377.64$ ) are different from those that prefer higher tariffs (average GDPPC $=\$ 8541.61$ ). Though this difference is quite noisy $(\mathrm{p}=0.504)$, it is suggestive that multilateral tariff cuts may naturally benefit developed countries. We examine this issue below within more realistic counterfactuals.

\section{Reversal of 1994-2000 Tariff Cuts}

Next, I abstract from the estimated exporter and importer non-tariff shocks used for the estimation of shape parameters to calculate the degree to which tariff cuts affected welfare, relative wages, and competition over the period 1994-2000. This was a particularly busy period of tariff reductions, with the Uruguay Round being implemented as well as the North American Free Trade Agreement. However, the counterfactual that we will examine is the reversal of tariff cuts that occurred over this period. This is because the internally consistent bilateral trade matrix from GTAP is defined for the year 2001, which is a year subsequent to most tariff cuts occurring. However, this counterfactual is still instructive as it will indicate where the benefits of the Uruguay Round likely occurred, and where any reverting trade war may have large effects.

The predicted effects of reversing tariff cuts that occurred between 1994-2000 are presented in the first column of Table6. The full results including wages, product competition, and overall competition, and presented in Table 7 of the online appendix. Broadly, the results indicate that a trade war of this sort would be damaging to many countries. In particular, many small countries (eg. Latvia, Malawi, Mozambique, Singapore, Tunisia, Vietnam) suffer significant welfare losses from the reversal of tariff cuts that occurred over 1994-2000. Countries like the US also lose, but do so modestly. Overall, roughly $69 \%$ of countries lose from the reversal of Uruguay Round tariff cuts.

There are also "winners" in the sense of preferring the reversal of 1994-2000 tariff cuts. One interesting example of this is Mexico (0.38\%), which over the period 1994-2000, signed a trade agreement with the US and Canada, but also participated in GATT negotiations and more generally sold goods in an environment of falling tariffs around the world. Indeed, this may suggest that the world-wide reductions in MFN tariffs mitigated the beneficial effects of NAFTA for Mexico, which is an example of the preference erosion discussed in Limão (2006).

As for other notable winners from a reverting trade war, Japan (0.26\%) and especially Korea $(2.47 \%)$ stand out.

Finally, I evaluate the difference in means of GDP per capita for winners and losers from 
reverting to 1994 tariffs. Indeed, countries that lose from the reversion of tariffs (average GDPPC $=\$ 7780.60$ ) are less developed than those that prefer higher tariffs (average GDPPC $=\$ 12,272)$. The p-value for this difference is 0.1056 . This is consistent with Uruguay Round concessions being offered disproportionately by developed countries, which opened their markets more so than developing countries ${ }^{20}$

\section{Worldwide Removal of Tariffs}

To evaluate the scope for future trade agreements, I now evaluate a counterfactual by removing all tariffs worldwide. Average tariffs at the end of the Uruguay Round were approximately $9.8 \%$, though it is worth noting that most of these tariffs were levied by developing countries. In contrast, US tariffs around this period, along with other developed countries, were already particularly low. So, the removal of tariffs will be skewed toward developing countries removing tariffs.

The welfare effects of this counterfactual are presented in the second column of Table 6. with full results in Table 8 of the online appendix. Here, $69 \%$ of countries are predicted to gain from the removal of post-Uruguay Round tariffs, which is exactly the same share of countries that are predicted to lose from reversing the Uruguay Round. However, these are not the same set of countries, where only $54 \%$ of countries lose under the reversal of 19942000 cuts and gain from full liberalization post-2000. India, Korea, and Vietnam are major countries predicted to gain substantially from the removal of post-2000 tariffs. However, a few markets are predicted to lose from future tariff cuts. For example, Malaysia and Portugal are worse off through many industries that have higher prices after the tariff shock. Venezuela suffers a $0.50 \%$ welfare loss. Further, consider the NAFTA zone - in contrast with the results from the reversal of the Uruguay Round, Canada, the US, and Mexico all gain from the removal of remaining tariffs worldwide. Finally, I evaluate the difference in means of GDP per capita for winners and losers from removing all tariffs. Indeed, I find that those countries that win from removing remaining tariffs (average GDPPC $=\$ 10,190.94$ ) are more developed than those that prefer tariffs at their 2000 levels (average GDPPC $=\$ 6,916.47$ ) then when evaluating the reversal of the Uruguay Round (p-value 0.162). This suggests, as borne out by tariff data, that future liberalization depends on developing countries removing their tariffs more so than developed ${ }^{21}$ As this is in stark contrast with those that were more

\footnotetext{
${ }^{20}$ Precisely, within industries, there is a positive and significant association between GDP per capita and the presence of a tariff cut between 1994-2000.

${ }^{21}$ Precisely, within industries, there is a negative and significant association between GDP per capita and
} 
likely to cut tariffs over 1994-2000, this may also explain why multilateral trade negotiations have stalled in recent years.

\section{Trans-Pacific Partnership}

As a final exercise, I simulate tariff cuts to free trade within the Trans-Pacific Partnership (TPP), which is a large proposed regional free-trade area between Australia, Brunei, Chile, Canada, Japan, Malaysia, Mexico, New Zealand, Peru, Singapore, the United States, and Vietnam. Relative to their year 2000 levels, I set applied tariffs between TPP nations to zero. This point of comparison is reasonable, since the TPP itself began in the early 2000's. However, one caveat in the forthcoming results is that the TPP is planned to include reductions in other non-tariff barriers, which are not modeled in this particular framework. Hence, the results here should be understood as estimating the effect of tariff reductions within the TPP.

The welfare effects for the TPP counterfactual are presented in the third column of Table 6. with full results in Table 9 of the online appendix. Here, we find rather provocative effects of the TPP, where not all countries party to the agreement benefit from it. Specifically, Chile, Malaysia, and to a very modest degree Australia, do not benefit from the agreement. The negative effects on Malaysia are, in absolute terms, larger than most other effects of the agreement $(-0.63 \%)$. Other member countries benefit from the agreement, and in the case of Vietnam, the benefit is relatively large $(0.63 \%)$.

A classic concern with regional trade agreements is the effect of the agreements on outsiders via trade diversion. Here, we find that many outsiders actually gain from the agreement (though the effects are extremely small). However, many small Asia-Pacific countries not party to the agreement - Indonesia and Thailand in particular - lose due to a general increase in regional competition. Hence, the results of this counterfactual show how a fairly straightforward agreement, with relatively few member countries, can have complex effects when countries differ in their productivity distributions.

\section{Comparison to CES}

As a final set of counterfactuals, I compare the results under a CES framework with those

presented for linear demand. Proposition 2 summarizes the non-equivalence between these existing tariffs after the year 2000 . 
models, when there is shape variation across and within industries. To execute this comparison, I need estimates for tariff elasticities and substitution elasticities $\sigma_{i}$ for each industry. To my knowledge there exists no joint estimates for both, so to abstract from differences in elasticities of substitution I assign $\sigma_{i}=4$ for all industries, and use tariff elasticities as estimated in section three. In Table 10 of the online technical appendix, I compare welfare results of all multi-lateral tariff shocks studied in this paper. The results indicate that there are some major differences in all tariff shocks between the models, and the qualitative welfare effects of tariff shocks differ for around $10 \%$ of countries for each counterfactual.22 In terms of quantitative differences, consider a $10 \%$ increase in tariffs by all nations. For Columbia, the welfare loss under CES $(-0.09 \%)$ is less than half of that from the linear model $(-0.27 \%)$. In contrast, for Malaysia, the welfare loss under CES $(-1.61 \%)$ is worse than in the linear model (-1.35\%). Exploring the differences and potentially unifying the features of these models will be a fruitful area of future work.

\section{Conclusion}

This paper has presented a novel approach to studying trade shocks. In particular, I have shown that highly complex trading relationships can be examined using simple linear algebra with readily available data and productivity estimates. The policy applications of the paper show a number of interesting features of proposed tariff cuts, including how proposed trade agreements may not benefit all insiders within the trade agreement.

There are a number of applications of these techniques that I intend to study in future work. One particularly fruitful application is to extend the techniques in this paper to include more than one factor of production. As the core of most criticism of trade agreements is focused on the distribution of gains and losses between workers and firms, allowing for different gains to accrue to capital and labor owners will provide novel guidance regarding the role of trade in magnifying or mitigating inequality.

\footnotetext{
${ }^{22}$ Precisely, for the common $10 \%$ increase in tariffs, the qualitative effects differ for $9.2 \%$ of countires. For the reversal of 1994-2000 cuts, the qualitative effects differ for $9.2 \%$ of countries. For removing remaining tariffs, the effects are qualitatively different for $11.5 \%$ of countries.
} 


\section{A Matrix form for Computation}

\section{A One-sector model}

To detail the computational implementation of the model, I will first detail the matrix solution for the case with one sector. In many ways, this is the canonical approach to studying firm heterogeneity, where we focus on within-industry reallocation via free entry conditions rather than cross-industry allocation via trade balance and labor market clearing conditions. Later, I will extend the matrix solution to the multi-sector framework. For this sub-section, we suppress $i$ 's.

To begin, recall that by combining labor market clearing and free entry conditions, entry is invariant to tariff shocks in the one sector model. Hence, $\widehat{N}_{j}=0$. With this result, the differentiated free-entry condition can be written as:

$$
\sum_{l=1}^{M} V_{j l} \widehat{\lambda}_{l}+\widehat{w}_{j} \sum_{l=1}^{M} V_{j l}=-\sum_{l=1}^{M} V_{j l} \widehat{t}_{j l} .
$$

The differentiated trade balance condition can written as:

$$
\begin{aligned}
\widehat{\lambda}_{l} \sum_{j=1}^{M}\left(k_{j}+1\right) V_{j l}+\sum_{j=1}^{M} k_{j} V_{j l} \widehat{w}_{j}+\sum_{j=1}^{M}\left(k_{j}+1\right) V_{j l} \widehat{t}_{j l} & =\sum_{h=1}^{M} \widehat{\lambda}_{h}\left(k_{l}+1\right) V_{l h} \\
& +\widehat{w}_{l} \sum_{h=1}^{M} k_{l} V_{l h}+\sum_{h=1}^{M}\left(k_{l}+1\right) V_{l h} \widehat{t}_{l h}
\end{aligned}
$$

As there are no sectors, the sectoral balancing conditions are not relevant for this solution.

Overall, in equations (23) and (24), the effects of a tariff shock are a function of changes to endogenous variables, observable trade values, observable tariff cuts, and productivity shape parameters that may vary across countries. Indeed, the latter shape parameters are the only unobserved terms required to predict the effects of tariff shocks on $\lambda_{l}$ 's and $w_{l}$ 's. Since there are no sectors, there is no sectoral optimization, so we ignore $\delta_{l}$ 's for this subsection.

Since there are many countries, we write the solution to $\hat{\lambda}_{l}$ 's and $\widehat{w}_{l}$ 's in matrix form. Before doing so, we will introduce some matrix notation and a few matrix functions to simplify the presentation of the solution (which will be especially useful in the forthcoming multisector model). First, identifying producing countries $(j)$ by rows and consuming countries (l) by columns, define $\mathbf{V}$ as the $M \times M$ bilateral matrix of aggregate (producer) trade values, $\mathbf{t}$ as the bilateral matrix of tariff factors (values of $\tau+1$ ) and $\widehat{\mathbf{t}}$ as the $M \mathrm{x} M$ bilateral matrix 
of tariff shocks.

To characterize within sector productivity variation, we define $\mathbf{k}$ as a $M \times M$ matrix of shape parameters, with the vector $\left(k_{1}, \ldots, k_{m}\right)^{T}$ in each column. While it may seem redundant to define the matrix of shape parameters in this way (rather than a one-column matrix), it will facilitate using the Hadamard (pointwise) product of two matrices to ease notation. Also, regarding the matrix of shape parameters, I will write $\mathbf{k}+\mathbf{1}$ to represent the matrix of shape parameters with one added to each shape estimate.

Further, in (23) and (24), there are a number of terms that require calculating row sums of a square matrix (e.g. $\widehat{w}_{j} \sum_{l=1}^{M} V_{j l}$ from free entry). To calculate row sums, we will use a short-hand matrix function $\mathbf{r}()$, which takes a matrix, sums up its rows, and places these row sums on a new diagonal matrix. Defining a $d x 1$ matrix of ones, $\mathbf{1}_{d}$, a $d x d$ identity matrix, $\mathbf{I}_{d x d}$, and using $\mathbf{V}$ as an example, the function $\mathbf{r}()$ can be written in matrix form as $\mathbf{r}(\mathbf{V})=\left(\mathbf{V} \mathbf{1}_{m} \mathbf{1}_{m}^{T}\right) \circ \mathbf{I}_{m x m}$, where $\circ$ represents the Hadamard product. Finally, row sums can be placed in a new $r \times 1$ matrix by writing $\mathbf{V} \mathbf{1}_{m}$. Both of these operations will be used extensively in the solution to follow.

Defining $\widehat{\lambda}$ and $\widehat{\mathbf{w}}$ as $M \mathrm{x} 1$ vectors of endogenous variables, changes to the system of equilibrium conditions in response to an arbitrary tariff shock can be written as follows:

$$
\mathbf{A}\left[\begin{array}{c}
\hat{\lambda} \\
\widehat{\mathbf{w}}
\end{array}\right]=\mathbf{B}
$$

where

$$
\mathbf{A}=\left[\begin{array}{cc}
\underset{m x m}{\mathbf{V}} & \mathbf{r}(\mathbf{V}) \\
m(x m \\
\left.\mathbf{r}((\mathbf{k}+\mathbf{1}) \circ \mathbf{V})^{T}\right)-\mathbf{V} \circ(\mathbf{k}+\mathbf{1}) & (\mathbf{k} \circ \mathbf{V})^{T}-\underset{m x m}{\mathbf{r}}(\mathbf{k} \circ \mathbf{V})
\end{array}\right]
$$

and

$$
\mathbf{B}=\left[\begin{array}{c}
-(\widehat{\mathbf{t}} \circ \mathbf{V}) \mathbf{1}_{\mathbf{m}} \\
-(\widehat{\mathbf{t}} \circ(\mathbf{k}+\mathbf{1}) \circ \mathbf{V})^{T} \mathbf{1}_{m}+(\widehat{\mathbf{t}} \circ(\mathbf{k}+\mathbf{1}) \circ \mathbf{V}) \mathbf{1}_{m}
\end{array}\right] .
$$

In (25), there are $2 M$ equations and $2 M$ unknowns. However, the $M$ trade balance conditions only consist of $M-1$ independent equations, and thus, we must impose a restriction on the 
equilibrium changes to wages via a choice of numeraire. Though this can be accomplished in a variety of ways, to stay consistent with the literature, we normalize world income to unity. Hence, this assumption imposes $\sum_{j=1}^{M} \widehat{w}_{j} \sum_{l=1}^{M} V_{j l}=0$ on changes to wages in response to any equilibrium. In matrix form:

$$
\left[\begin{array}{ll}
\mathbf{0} & \mathbf{1}_{m}^{T} \mathbf{r}(\mathbf{V})
\end{array}\right]\left[\begin{array}{l}
\widehat{\lambda} \\
\widehat{\mathbf{w}}
\end{array}\right]=0
$$

Here, $\mathbf{1}_{m}^{T} \mathbf{r}(\mathbf{V})$ is a $1 \mathrm{x} M$ matrix with total revenues in each element of the matrix. To implement (26) within (25), we simply replace the last row of $\mathbf{A}$ with (26) (in matrix form) and the last row of $\mathbf{B}$ with a zero, defining the new matrices as $\widetilde{\mathbf{A}}$ and $\widetilde{\mathbf{B}} \cdot 23$ To summarize, after imposing the numeraire, the equation we take to the data to generate counterfactuals is the following:

$$
\left[\begin{array}{l}
\widehat{\lambda} \\
\widehat{\mathbf{w}}
\end{array}\right]=\widetilde{\mathbf{A}}^{-1} \widetilde{\mathbf{B}}
$$

I now extend the comparative statics to account for a non-trivial industry dimension.

\section{B Multi-sector model}

In Section 2.4, I derived the effects of an arbitrary tariff shock on the multi-sector model, where I showed that the response of endogenous variables to an arbitrary tariff shock could be written as a linear function of trade data an productivity shape parameters. This function was constructed from $M \mathrm{x} I$ free entry conditions in (14), $M$ labor market conditions in (15), $M$ trade balance conditions in (16), a numeraire restriction in (17), and $M \mathrm{x} I$ sectoral optimization conditions (18). I now show how to arrange these functions in matrix form.

\footnotetext{
${ }^{23}$ The row of choice does not matter in this normalization within the rows defined by the trade balance condition. Further, whether $\widetilde{\mathbf{A}}$ is invertible is an empirical question, and we verify for each counterfactual that the Jacobian matrix is indeed full rank.
} 
First, we define $\mathbf{V}$ as a block diagonal matrix of the industry bilateral trade matrices,

$$
\mathbf{V}=\left[\begin{array}{ccccc}
\mathbf{V}^{\mathbf{1}} & \ldots & \mathbf{0}_{m x m} & \ldots & \mathbf{0}_{m x m} \\
\vdots & \ddots & \vdots & & \vdots \\
\mathbf{0}_{m x m} & \ldots & \mathbf{V}^{\mathbf{i}} & \ldots & \mathbf{0}_{m x m} \\
\vdots & & \vdots & \ddots & \vdots \\
\mathbf{0}_{m x m} & \ldots & \mathbf{0}_{m x m} & \ldots & \mathbf{V}^{\mathbf{I}}
\end{array}\right]
$$

where $\mathbf{0}_{m x m}$ is a $M \mathrm{x} M$ matrix of zeros. Similarly, the industry level shape matrices and industry-level tariffs parameters will also be stored in a block diagonal matrix:

$$
\mathbf{k}=\left[\begin{array}{ccccc}
\mathbf{k}^{\mathbf{1}} & \ldots & \mathbf{0}_{m x m} & \ldots & \mathbf{0}_{m x m} \\
\vdots & \ddots & \vdots & & \vdots \\
\mathbf{0}_{m x m} & \ldots & \mathbf{k}^{\mathbf{i}} & \ldots & \mathbf{0}_{m x m} \\
\vdots & & \vdots & \ddots & \vdots \\
\mathbf{0}_{m x m} & \ldots & \mathbf{0}_{m x m} & \ldots & \mathbf{k}^{\mathbf{I}}
\end{array}\right] \quad \mathbf{t}=\left[\begin{array}{ccccc}
\mathbf{t}^{\mathbf{1}} & \ldots & 0 & \ldots & \mathbf{0}_{m x m} \\
\vdots & \ddots & \vdots & & \vdots \\
\mathbf{0}_{m x m} & \ldots & \mathbf{t}^{\mathbf{i}} & \ldots & \mathbf{0}_{m x m} \\
\vdots & & \vdots & \ddots & \vdots \\
\mathbf{0}_{m x m} & \ldots & \mathbf{0}_{m x m} & \ldots & \mathbf{t}^{\mathbf{I}}
\end{array}\right]
$$

Finally, define $\mathbf{E}^{\mathbf{h}}=\mathbf{t}^{\mathbf{h}} \circ \mathbf{V}^{\mathbf{h}} \circ\left(\frac{2 \mathbf{k}^{\mathbf{h}}+3}{2 \mathbf{k}^{\mathbf{h}}+2}\right)$ as adjusted expenditures as in the sectoral optimization condition, where the division $\frac{2 \mathbf{k}^{\mathbf{h}}+3}{2 \mathbf{k}^{\mathbf{h}}+2}$ is mean to be element by element. With this industry level matrix of adjusted expenditures, we define $\mathbf{E}$ as a block diagonal matrix of $\mathbf{E}^{\mathbf{h}}$ 's.

For the endogenous variables, we define $\widehat{\lambda}^{h}=\left[\lambda_{h 1}, \ldots, \lambda_{h m}\right]$ and $\widehat{\mathbf{N}}^{h}=\left[\widehat{N}_{h 1}, \ldots, \widehat{N}_{h m}\right]$ as industry level vectors of constraint multipliers and entering firms. Combining by industry, and taking the transpose of each, we have the following column matrices of percent changes to constraint multipliers and entering firms $\widehat{\lambda}=\left[\widehat{\lambda}^{1}, \ldots, \widehat{\lambda}^{I}\right]^{T}$ and $\widehat{\mathbf{N}}=\left[\widehat{\mathbf{N}}^{1}, \ldots, \widehat{\mathbf{N}}^{I}\right]^{T}$. Finally, we define the column matrix of percent changes to wages as $\widehat{\mathbf{w}}=\left[\widehat{w}_{1}, \ldots, \widehat{w}_{m}\right]^{T}$, and the column matrix of $\delta$ 's as $\widehat{\delta}=\left[\widehat{\delta}_{1}, \ldots, \widehat{\delta}_{m}\right]^{T}$.

As in the one sector model, when writing the matrix solution to changes in equilibrium conditions, we will use a number of matrices to construct row sums, and place these row sums in new matrices. The column matrix of ones, $\mathbf{1}_{d}$ is defined similar to above, as are standard identity matrices, $\mathbf{I}_{d x d}$. However, we must extend the concept of the identity matrix to $r$ rows and $m$ columns, where $m$ is a factor of $r$ but not equal to $r$. Precisely, $\mathbf{I}_{r x m}=\left[\mathbf{I}_{1}^{m x m}, \underset{2}{m x m} \ldots, \underset{r / m}{\mathbf{I}_{m x m}}\right]^{T}$ where $r / m \mathbf{I}_{m x m}$ identity matrices are stacked on top of one another.

In the solution below, the most common (and unwieldy) matrix operation will be taking 
row sums of a block diagonal matrix and placing those sums in a matrix that might not be of the same dimension. On $\mathbf{V}$, row sums placed on the diagonal of a matrix with the same dimensions is accomplished via $\left(\mathbf{V} \mathbf{1}_{r} \mathbf{1}_{r}^{T}\right) \circ \mathbf{I}_{r x r}$. This is commonly used for endogenous variables that vary by country and industry, like $\lambda_{i l}$. Again using $\mathbf{V}$, row sums placed on the repeating "diagonals" of a matrix with $r$ rows and $m$ columns is accomplished via $\left(\mathbf{V} \mathbf{1}_{r} \mathbf{1}_{r}^{T}\right) \circ \mathbf{I}_{r x m}$. This is commonly used when collecting wage effects on the equilibrium. Finally, within trade balance I must sum up total producer revenues scaled by $k$ and place these sums on a $M \times x M$ matrix. This is done via $\left(\mathbf{I}_{r x m}^{T}(\mathbf{V} \circ \mathbf{k}) \mathbf{1}_{r} \mathbf{1}_{m}^{T}\right) \circ \mathbf{I}_{m x m}$.

Using the matrix definitions outlined above, and the system of equilibrium conditions in (14), (15), (16), and (18), percent changes to constraint multipliers, entering firms, wages, and level changes to tariff revenue, are defined by the following solution,

$$
\mathbf{A}\left[\begin{array}{c}
\widehat{\lambda} \\
\widehat{\mathbf{N}} \\
\widehat{\mathbf{w}} \\
\widehat{\delta}
\end{array}\right]=\mathbf{B},
$$

where $\mathbf{A}$ and $\mathbf{B}$ are written as,

$$
\mathbf{A}=\left[\begin{array}{cccc}
\left(((\mathbf{k}+1) \circ \mathbf{E})^{T} \mathbf{1}_{r} \mathbf{1}_{r}^{T}\right) \circ \mathbf{I}_{r x r} & -\mathbf{E}^{T} & (\mathbf{E} \circ \mathbf{k})^{T} \mathbf{I}_{r x m} & -\left(\mathbf{E}^{T} \mathbf{1}_{r} \mathbf{1}_{m}^{T}\right) \circ \mathbf{I}_{r x m} \\
\mathbf{V} & \mathbf{0}_{r x r} & \left(\mathbf{V} \mathbf{1}_{r} \mathbf{1}_{m}^{T}\right) \circ \mathbf{I}_{r x m} & \mathbf{0}_{r x m} \\
& \left(\left(\mathbf{V} \mathbf{1}_{r} \mathbf{1}_{m}^{T}\right) \circ \mathbf{I}_{r x m}\right)^{T} & & \mathbf{0}_{m x m} \\
\mathbf{0}_{m x r} & -\mathbf{0}_{m x m} & \\
\left.\left(((\mathbf{k}+\mathbf{1}) \circ \mathbf{V})^{T} \mathbf{1}_{r} \mathbf{1}_{m}^{T}\right) \circ \mathbf{I}_{r x m}\right)^{T} & -\left(\left(\mathbf{V} \mathbf{1}_{r} \mathbf{1}_{m}^{T}\right) \circ \mathbf{I}_{r x m}\right)^{T} & -\left(\mathbf{I}_{r x m}^{T}(\mathbf{V} \circ \mathbf{k}) \mathbf{1}_{r} \mathbf{1}_{m}^{T}\right) \circ \mathbf{I}_{m x m} & \mathbf{0}_{m x m} \\
-\mathbf{I}_{r x m}^{T}(\mathbf{V} \circ(\mathbf{k}+\mathbf{1})) &
\end{array}\right]
$$

and,

$$
\mathbf{B}=\left[\begin{array}{c}
-(\mathbf{E} \circ \mathbf{k} \circ \widehat{\mathbf{t}})^{T} \mathbf{1}_{r} \\
-(\mathbf{V} \circ \widehat{\mathbf{t}})^{\mathbf{1}_{r}} \\
\mathbf{0}_{m x 1} \\
-\left((\mathbf{V} \circ(\mathbf{k}+1) \circ \widehat{\mathbf{t}}) \mathbf{I}_{r x m}\right)^{T} \mathbf{1}_{r}+\left(\mathbf{I}_{r x m}^{T}(\mathbf{V} \circ(\mathbf{k}+1) \circ \widehat{\mathbf{t}})\right) \mathbf{1}_{r}
\end{array}\right]
$$

Here, the first rows of the block matrix represents the differentiated sectoral balance conditions, the second row the free entry conditions, the third row the labor market clearing conditions, and the fourth the trade balance conditions. Again, the $M$ trade balance con- 
ditions will only consist of $M-1$ independent equations, and hence, we normalize world income to unity as the choice of numeraire in (17). As described in section A.1, we arrange this equation in matrix form, and replace the last row of $\mathbf{A}$ and $\mathbf{B}$ with this restriction. 


\section{References}

Allen, Treb, Costas Arkolakis \& Yuta Takahashi (2014), 'Universal gravity', NBER Working Paper (w20787).

Arkolakis, Costas, Arnaud Costinot \& Andrés Rodríguez-Clare (2011), 'New trade theories, same old gains?', American Economic Review 102(1), 94-130.

Arkolakis, Costas, Arnaud Costinot, Dave Donaldson \& Andrés Rodríguez-Clare (2012), 'The elusive pro-competitive effects of trade', Unpublished, MIT .

Atkeson, Andrew \& Ariel Burstein (2008), 'Pricing-to-market, trade costs, and international relative prices', The American Economic Review 98(5), 1998-2031.

Bagwell, Kyle \& Robert Staiger (2015), 'Delocation and trade agreements in imperfectly competitive markets', Research in Economics 69(2), 132-156.

Bagwell, Kyle \& Robert W. Staiger (2012), 'The economics of trade agreements in the linear cournot delocation model', Journal of International Economics 88, 32-46.

Bagwell, Kyle \& Seung Hoon Lee (2014), 'Optimal trade policies with delocation and selection', unpublished, Stanford University .

Bloom, Nicholas, Benn Eifert, Aprajit Mahajan, David McKenzie \& John Roberts (2013), 'Does management matter? evidence from india', Quarterly Journal of Economics 128(1), $1-51$.

Bloom, Nick \& John Van Reenen (2006), 'Measuring and explaining management practices across firms and countries', Quarterly Journal of Economics 122(4), 1351-1408.

Bombardini, Matilde, Christopher J Kurz \& Peter M Morrow (2012), 'Ricardian trade and the impact of domestic competition on export performance', Canadian Journal of Economics/Revue canadienne d'économique 45(2), 585-612.

Breinlich, Holger \& Alejandro Cuñat (2015), 'Tariffs, trade and productivity: A quantitative evaluation of heterogeneous firm models', Economic Journal (forthcoming).

Bremus, Franziska, Claudia Buch, Katheryn Russ \& Monika Schnitzer (2013), 'Big banks and macroeconomic outcomes: Theory and cross-country evidence of granularity', NBER Working Paper (19093). 
Brouhns, Natacha, Michel Denuit \& Jeroen K Vermunt (2002), 'A poisson log-bilinear regression approach to the construction of projected lifetables', Insurance: Mathematics and Economics 31(3), 373-393.

Burstein, Ariel \& Javier Cravino (2015), 'Measured aggregate gains from international trade', American Economic Journal, Macroeconomics 7(2), 181-218.

Caliendo, Lorenzo \& Fernando Parro (2015), 'Estimates of the trade and welfare effects of nafta', Review of Economic Studies 82(1), 1-44.

Caron, Justin, Thibault Fally \& James R Markusen (2015), 'Skill premium and trade puzzles: A solution linking production and preferences', Quarterly Journal of Economics (forthcoming).

Cebeci, Tolga, Ana M Fernandes, Caroline Freund \& Martha Denisse Pierola (2012), 'Exporter dynamics database', World Bank Working Paper .

Chaney, Thomas (2008), 'Distorted gravity: the intensive and extensive margins of international trade', The American Economic Review 98(4), 1707-1721.

Combes, Pierre-Philippe, Gilles Duranton, Laurent Gobillon, Diego Puga \& Sébastien Roux (2012), 'The productivity advantages of large cities: Distinguishing agglomeration from firm selection', Econometrica 80(6), 2543-2594.

Costinot, Arnaud \& Andrés Rodríguez-Clare (2013), 'Trade theory with numbers: Quantifying the consequences of globalization', Handbook of International Economics .

Davidson, Russell \& Emmanuel Flachaire (2008), 'The wild bootstrap, tamed at last', Journal of Econometrics 146(1), 162-169.

de Blas, Beatriz \& Katheryn N Russ (2015), 'Understanding markups in the open economy', American Economic Journal, Macroeconomics (forthcoming).

Dekle, Robert, Jonathan Eaton \& Samuel Kortum (2008), 'Global rebalancing with gravity: Measuring the burden of adjustment', IMF Staff Papers 55(3), 511-540.

Demidova, Svetlana (2008), 'Productivity improvements and falling trade costs: boon or bane?', International Economic Review 49(4), 1437-1462. 
Demidova, Svetlana. \& Andrés Rodríguez-Clare (2015), 'The simple analytics of the melitz model in a small open economy', Journal of International Economics 96(1), 18-36.

Di Giovanni, Julian, Andrei A Levchenko \& Romain Ranciere (2011), 'Power laws in firm size and openness to trade: Measurement and implications', Journal of International Economics 85(1), 42-52.

Eaton, Jonathan \& Samuel Kortum (2002), 'Technology, geography, and trade', Econometrica 70(5), 1741-1779.

Eaton, Jonathan, Samuel Kortum \& Francis Kramarz (2011), 'An anatomy of international trade: Evidence from french firms', Econometrica 79(5), 1453-1498.

Edmond, Chris, Virgiliu Midrigan \& Daniel Yi Xu (2015), 'Competition, markups, and the gains from international trade', American Economic Review (forthcoming).

Feenstra, Robert C (2014), 'Restoring the product variety and pro-competitive gains from trade with heterogeneous firms and bounded productivity', NBER Working Paper (19833).

Foster, Lucia, John Haltiwanger \& Chad Syverson (2008), 'Reallocation, firm turnover, and efficiency: Selection on productivity or profitability?', The American Economic Review 98(1), 394-425.

Head, Keith, Thierry Mayer \& Mathias Thoenig (2014), 'Welfare and trade without pareto', American Economic Review 104(5), 310-316.

Helpman, Elhanan, Marc J Melitz \& Stephen R Yeaple (2004), 'Export versus fdi with heterogeneous firms', American Economic Review 94(1), 300-316.

Helpman, Elhanan, Marc Melitz \& Yona Rubinstein (2008), 'Estimating trade flows: Trading partners and trading volumes', The Quarterly Journal of Economics 123(2), 441-487.

Hsieh, Chang-Tai \& Ralph Ossa (2015), 'A global view of productivity growth in china', NBER Working Paper (16778).

Inwood, Kris \& Ian Keay (2013), 'Trade policy and industrial development: iron and steel in a small open economy, 1870-1913', Canadian Journal of Economics/Revue canadienne d'économique 46(4), 1265-1294. 
Limão, Nuno (2006), 'Preferential vs. multilateral trade liberalization: evidence and open questions', World Trade Review 5(02), 155-176.

Mayer, Thierry \& Gianmarco IP Ottaviano (2008), 'The happy few: The internationalisation of european firms', Intereconomics 43(3), 135-148.

Melitz, Marc (2003), 'The impact of trade on aggregate industry productivity and intraindustry reallocations', Econometrica 71(6), 1695-1725.

Melitz, Marc \& Gianmarco Ottaviano (2008), 'Market size, trade, and productivity', The review of economic studies $\mathbf{7 5}(1)$, 295-316.

Melitz, Marc J \& Stephen J Redding (2015), 'New trade models, new welfare implications', American Economic Review (forthcoming).

Neary, J Peter (2009), 'International trade in general oligopolistic equilibrium', Unpublished Manuscript, University of Oxford .

Okubo, Toshihiro \& Eiichi Tomiura (2014), 'Skew productivity distributions and agglomeration: Evidence from plant-level data', Regional Studies 48(9), 1514-1528.

Ossa, Ralph (2011), 'A 'new trade' theory of gatt/wto negotiations', Journal of Political Economy 119(1), 122-152.

Ossa, Ralph (2014), 'Trade wars and trade talks with data', American Economic Review 104(12), 4104-46.

Saggi, Kamal \& Nese Sara (2008), 'National treatment at the wto: The roles of product and country heterogeneity', International Economic Review 49(4), 1365-1394.

Spearot, Alan (2014), 'Tariffs, competition, and the long of firm heterogeneity models', Working Paper, UC Santa Cruz .

Spearot, Alan C. (2013), 'Variable demand elasticities and tariff liberalization', Journal of International Economics 91(2), 26-41.

Venables, Anthony J. (1985), 'Trade and trade policy with imperfect competition: The case of identical products and free entry', Journal of International Economics 19(1), 1-19. 
Table 1: Shape Estimates - Industry Summary

\begin{tabular}{|c|c|c|c|c|c|c|}
\hline \multirow[b]{2}{*}{ Code } & \multirow[b]{2}{*}{ Industry } & \multicolumn{3}{|c|}{ Shape Estimates, $k$} & \multirow[b]{2}{*}{ St. Dev } & \multirow{2}{*}{$\begin{array}{l}\text { Significant } \\
\text { Shape Var. }\end{array}$} \\
\hline & & GTAP & Mean & Median & & \\
\hline PDR & Paddy rice & 1 & 6.63 & 5.80 & 3.01 & $* * *$ \\
\hline WHT & Wheat & 2 & 6.78 & 5.36 & 3.14 & $* * *$ \\
\hline GRO & Cereal grains n.e.c. & 3 & 5.07 & 4.78 & 1.60 & $* * *$ \\
\hline V_F & Vegetables, fruit, nuts & 4 & 3.89 & 2.63 & 3.45 & $* * *$ \\
\hline OSD & Oil seeds & 5 & 3.19 & 2.62 & 1.59 & $* * *$ \\
\hline PFB & Plant-based fibers & 7 & 2.79 & 2.56 & 0.67 & $* * *$ \\
\hline OCR & Crops n.e.c. & 8 & 2.34 & 1.95 & 0.97 & $* * *$ \\
\hline CTL & Bovine cattle, sheep and goats, horses & 9 & 4.59 & 4.17 & 1.58 & $* * *$ \\
\hline OAP & Animal products n.e.c. & 10 & 2.62 & 2.30 & 1.33 & $* * *$ \\
\hline WOL & Wool, silk-worm cocoons & 12 & 4.42 & 3.78 & 1.93 & $* * *$ \\
\hline FRS & Forestry & 13 & 3.64 & 2.95 & 2.00 & $* * *$ \\
\hline FSH & Fishing & 14 & 4.20 & 3.13 & 3.05 & $* * *$ \\
\hline $\mathrm{COA}$ & Coal & 15 & 5.86 & 4.68 & 2.73 & $* * *$ \\
\hline OIL & Oil & 16 & 7.42 & 7.02 & 1.20 & $* * *$ \\
\hline OMN & Minerals n.e.c. & 18 & 3.29 & 3.02 & 1.10 & $* * *$ \\
\hline CMT & Bovine meat prods & 19 & 3.67 & 3.02 & 2.46 & $* * *$ \\
\hline OMT & Meat products n.e.c. & 20 & 3.87 & 2.80 & 2.52 & $* * *$ \\
\hline VOL & Vegetable oils and fats & 21 & 3.33 & 2.56 & 1.59 & $* * *$ \\
\hline MIL & Dairy products & 22 & 2.31 & 1.73 & 1.62 & $* * *$ \\
\hline PCR & Processed rice & 23 & 5.45 & 4.50 & 2.75 & $* * *$ \\
\hline SGR & Sugar & 24 & 4.64 & 4.12 & 1.96 & $* * *$ \\
\hline OFD & Food products n.e.c. & 25 & 2.52 & 1.55 & 2.88 & $* * *$ \\
\hline $\mathrm{B}_{-} \mathrm{T}$ & Beverages and tobacco products & 26 & 2.02 & 1.12 & 2.56 & $* * *$ \\
\hline TEX & Textiles & 27 & 1.79 & 1.49 & 0.90 & $* * *$ \\
\hline WAP & Wearing apparel & 28 & 2.21 & 1.69 & 1.52 & $* * *$ \\
\hline LEA & Leather products & 29 & 2.46 & 1.58 & 2.64 & $* * *$ \\
\hline LUM & Wood products & 30 & 2.18 & 1.34 & 2.02 & $* * *$ \\
\hline PPP & Paper products, publishing & 31 & 2.40 & 1.76 & 2.05 & $* * *$ \\
\hline P_C & Petroleum, coal products & 32 & 4.70 & 3.82 & 2.38 & $* * *$ \\
\hline $\mathrm{CRP}$ & Chemical, rubber, plastic products & 33 & 2.32 & 1.87 & 1.58 & $* * *$ \\
\hline NMM & Mineral products n.e.c. & 34 & 2.39 & 1.94 & 1.51 & $* * *$ \\
\hline I_S & Ferrous metals & 35 & 3.52 & 2.25 & 3.59 & $* * *$ \\
\hline NFM & Metals n.e.c. & 36 & 3.80 & 2.76 & 2.54 & $* * *$ \\
\hline FMP & Metal products & 37 & 3.11 & 1.76 & 3.18 & $* * *$ \\
\hline MVH & Motor vehicules and parts & 38 & 2.36 & 1.56 & 2.29 & $* * *$ \\
\hline OTN & Transport equipment n.e.c. & 39 & 2.78 & 2.56 & 0.83 & $* * *$ \\
\hline ELE & Electronic equipment & 40 & 2.06 & 1.94 & 0.52 & $* * *$ \\
\hline OME & Machinery and equipment n.e.c. & 41 & 2.02 & 1.86 & 0.66 & $* * *$ \\
\hline $\mathrm{OMF}$ & Manufactures n.e.c. & 42 & 1.93 & 1.44 & 1.29 & $* * *$ \\
\hline
\end{tabular}

Notes: This table presents mean and median shape estimates by industry. "Significant Shape Var." reports when shape homogeneity within the given industry can be rejected at the $1 \%$ level using a likelihood ratio test. 
Table 2: Shape Estimates - Country Summary

\begin{tabular}{|c|c|c|c|c|c|c|c|}
\hline \multirow[b]{2}{*}{ Country } & \multirow[b]{2}{*}{ \# Ind } & \multicolumn{2}{|c|}{ Shape $(k)$ Estimates } & \multirow[b]{2}{*}{ Country } & \multirow[b]{2}{*}{ \# Ind } & \multicolumn{2}{|c|}{ Shape $(k)$ Estimates } \\
\hline & & $\bar{k}_{j}$ & AvgT & & & $\bar{k}_{j}$ & AvgT \\
\hline Albania & 18 & 5.49 & 0.47 & Malaysia & 37 & 2.83 & -0.77 \\
\hline Argentina & 39 & 3.26 & -0.64 & Malta & 23 & 4.36 & 0.26 \\
\hline Australia & 39 & 2.57 & -0.92 & Mexico & 35 & 2.80 & -0.68 \\
\hline Austria & 33 & 2.82 & -0.75 & Morocco & 30 & 3.18 & -0.37 \\
\hline Bangladesh & 25 & 4.77 & 0.32 & Mozambique & 29 & 5.59 & 0.36 \\
\hline Belgium & 25 & 4.30 & 0.14 & Netherlands & 39 & 2.91 & -0.97 \\
\hline Botswana & 1 & 5.48 & 0.59 & New Zealand & 36 & 2.75 & -0.69 \\
\hline Brazil & 36 & 3.29 & -0.59 & Peru & 33 & 2.78 & -0.32 \\
\hline Bulgaria & 34 & 2.99 & -0.38 & Philippines & 32 & 2.43 & -0.75 \\
\hline Canada & 38 & 2.40 & -1.11 & Poland & 34 & 3.17 & -0.48 \\
\hline Chile & 33 & 2.68 & -0.72 & Portugal & 31 & 2.57 & -0.63 \\
\hline China & 39 & 2.91 & -0.91 & Romania & 32 & 3.46 & -0.13 \\
\hline Colombia & 35 & 3.09 & -0.25 & Russia & 37 & 3.21 & -0.41 \\
\hline Croatia & 28 & 3.73 & 0.04 & Singapore & 37 & 3.09 & -0.65 \\
\hline Cyprus & 28 & 3.35 & 0.00 & Slovakia & 32 & 3.44 & -0.11 \\
\hline Czech Rep. & 33 & 2.99 & -0.39 & Slovenia & 28 & 2.83 & -0.26 \\
\hline Denmark & 36 & 2.97 & -0.81 & South Africa & 36 & 2.55 & -0.72 \\
\hline Estonia & 28 & 3.59 & 0.13 & Spain & 37 & 2.55 & -1.02 \\
\hline Finland & 33 & 2.81 & -0.58 & Sri Lanka & 31 & 3.85 & -0.25 \\
\hline France & 38 & 2.58 & -1.11 & Sweden & 35 & 3.38 & -0.71 \\
\hline Germany & 39 & 2.57 & -1.25 & Switzerland & 36 & 2.40 & -0.95 \\
\hline Greece & 31 & 2.60 & -0.68 & Taiwan & 35 & 2.32 & -1.08 \\
\hline Hong Kong & 36 & 2.67 & -0.87 & Tanzania & 28 & 2.86 & -0.32 \\
\hline Hungary & 34 & 2.92 & -0.36 & Thailand & 37 & 2.83 & -0.74 \\
\hline India & 39 & 2.89 & -1.01 & Tunisia & 25 & 3.29 & -0.17 \\
\hline Indonesia & 35 & 3.15 & -0.72 & Turkey & 38 & 3.32 & -0.49 \\
\hline Ireland & 29 & 2.40 & -0.74 & Uganda & 23 & 4.32 & 0.25 \\
\hline Italy & 38 & 2.53 & -1.14 & United Kingdom & 39 & 2.72 & -1.16 \\
\hline Japan & 39 & 2.84 & -0.95 & United States & 39 & 2.42 & -1.23 \\
\hline Korea & 36 & 2.74 & -0.95 & Uruguay & 35 & 3.32 & -0.29 \\
\hline Latvia & 30 & 3.97 & 0.16 & Venezuela & 34 & 3.97 & -0.05 \\
\hline Lithuania & 32 & 4.28 & 0.09 & Vietnam & 35 & 3.58 & -0.22 \\
\hline Luxembourg & 2 & 1.77 & -0.30 & Zambia & 27 & 3.92 & 0.05 \\
\hline Madagascar & 22 & 3.40 & -0.01 & Zimbabwe & 30 & 3.18 & -0.25 \\
\hline Malawi & 25 & 4.77 & 0.32 & & & & \\
\hline
\end{tabular}

Notes: This table presents average shape estimates by country, including the number of industries for which shape can be estimated (\# Ind), the average shape estimate for each country across industries, and finally the average t-statistic (AvgT) for each country when evaluating shape relative to the industry mean. The shape estimates for aggregated regions are available on the author's website. 
Table 3: Welfare Effects $(\% \Delta E V)$ of a Unilateral $10 \%$ Increase in all US Tariffs

\begin{tabular}{|c|c|c|c|c|c|c|c|}
\hline & Aggregate & 57 & ector & & Aggregate & 57 & ector \\
\hline Country & $\bar{k}$ & $\bar{k}_{i}$ & $k_{i j}$ & Country & $\bar{k}$ & $\bar{k}_{i}$ & $k_{i j}$ \\
\hline Albania & 0.15 & 0.26 & 0.25 & Malaysia & -1.03 & -0.93 & -0.94 \\
\hline Argentina & -0.09 & -0.07 & -0.07 & Malta & -0.11 & -0.14 & -0.28 \\
\hline Australia & -0.10 & -0.08 & -0.08 & Mexico & -0.57 & -0.58 & -0.57 \\
\hline Austria & -0.09 & -0.05 & -0.06 & Morocco & -0.06 & 0.16 & 0.13 \\
\hline Bangladesh & -0.05 & -0.08 & -0.08 & Mozambique & -0.02 & 0.03 & 0.00 \\
\hline Belgium & -0.18 & -0.29 & -0.27 & Netherlands & -0.08 & -0.08 & -0.04 \\
\hline Botswana & -0.20 & 0.04 & 0.01 & New Zealand & -0.19 & -0.09 & -0.10 \\
\hline Brazil & -0.12 & -0.12 & -0.12 & Peru & -0.15 & -0.11 & -0.10 \\
\hline Bulgaria & -0.01 & 0.01 & 0.01 & Philippines & -0.27 & -0.19 & -0.21 \\
\hline Canada & -0.76 & -0.80 & -0.78 & Poland & 0.02 & 0.13 & 0.12 \\
\hline Chile & -0.23 & -0.10 & -0.11 & Portugal & 0.03 & 0.07 & 0.09 \\
\hline China & -0.20 & -0.18 & -0.17 & Romania & 0.01 & 0.14 & 0.15 \\
\hline Colombia & -0.23 & -0.16 & -0.15 & Russia & -0.15 & -0.09 & -0.10 \\
\hline Croatia & -0.01 & -0.04 & -0.03 & Singapore & -0.37 & 0.19 & 0.34 \\
\hline Cyprus & -0.06 & 0.35 & 0.37 & Slovakia & 0.01 & 0.01 & 0.03 \\
\hline Czech Rep. & -0.06 & -0.03 & -0.02 & Slovenia & -0.04 & -0.01 & 0.01 \\
\hline Denmark & -0.13 & -0.15 & -0.14 & South Africa & -0.19 & -0.27 & -0.23 \\
\hline Estonia & -0.07 & 0.05 & 0.06 & Spain & -0.03 & -0.03 & -0.02 \\
\hline Finland & -0.17 & -0.14 & -0.14 & Sri Lanka & -0.29 & -0.76 & -0.77 \\
\hline France & -0.07 & 0.00 & 0.01 & Sweden & -0.17 & -0.14 & -0.13 \\
\hline Germany & -0.11 & -0.09 & -0.09 & Switzerland & -0.26 & -0.23 & -0.21 \\
\hline Greece & 0.03 & 0.07 & 0.07 & Taiwan & -0.34 & -0.26 & -0.28 \\
\hline Hong Kong & -0.09 & -0.05 & 0.00 & Tanzania & 0.03 & 0.05 & 0.06 \\
\hline Hungary & -0.13 & -0.10 & -0.09 & Thailand & -0.40 & -0.11 & -0.09 \\
\hline India & -0.07 & -0.03 & -0.03 & Tunisia & -0.06 & 1.07 & 0.86 \\
\hline Indonesia & -0.31 & -0.24 & -0.23 & Turkey & -0.11 & 0.37 & 0.24 \\
\hline Ireland & -0.52 & -0.84 & -0.83 & Uganda & 0.09 & 0.12 & 0.11 \\
\hline Italy & -0.07 & 0.16 & 0.14 & United Kingdom & -0.07 & -0.02 & 0.01 \\
\hline Japan & -0.09 & -0.11 & -0.10 & United States & 0.25 & 0.18 & 0.20 \\
\hline Korea & -0.29 & -0.39 & -0.36 & Uruguay & -0.04 & -0.05 & -0.04 \\
\hline Latvia & 0.09 & 0.16 & 0.19 & Venezuela & -0.29 & -0.21 & -0.19 \\
\hline Lithuania & 0.04 & 0.09 & 0.11 & Vietnam & 0.14 & 1.10 & 1.10 \\
\hline Luxembourg & -0.01 & 0.09 & 0.10 & Zambia & -0.04 & -0.03 & -0.03 \\
\hline Madagascar & -0.02 & 0.67 & 0.60 & Zimbabwe & -0.08 & 0.02 & -0.04 \\
\hline Malawi & -0.18 & -0.45 & -0.29 & & & & \\
\hline
\end{tabular}

Notes: This table presents the equivalent variation of a $10 \%$ increase in US tariffs from their 2000 levels. In the first column, we aggregate to one sector and assume that productivity shape is common across all countries $(\bar{k})$. In the second column, we use the 57 sector model, assuming that productivity shape is common across countries within each industry $\left(\bar{k}_{i}\right)$. Finally, in the third column, we allow for across and within industry variation in shape $\left(k_{i j}\right)$. The results for aggregated regions are available upon request. 
Table 4: Effects of Unilateral Tariff Cuts - All Countries

\begin{tabular}{|c|c|c|c|c|c|c|c|}
\hline \multirow[b]{2}{*}{ Country } & \multicolumn{2}{|c|}{$\% \Delta E V_{l}$} & \multirow{2}{*}{$\begin{array}{c}\text { Share } \widehat{a}_{i l}<0 \\
10 \% \Uparrow\end{array}$} & \multirow[b]{2}{*}{ Country } & \multicolumn{2}{|c|}{$\% \Delta E V_{l}$} & \multirow{2}{*}{$\begin{array}{c}\text { Share } \widehat{a}_{i l}<0 \\
10 \% \Uparrow\end{array}$} \\
\hline & $10 \% \Uparrow$ & All $\Downarrow$ & & & $10 \% \Uparrow$ & All $\Downarrow$ & \\
\hline Albania & 0.77 & -0.37 & 0.07 & Malaysia & 2.44 & -1.15 & 0.53 \\
\hline Argentina & 0.29 & -0.13 & 0.02 & Malta & 2.84 & -1.37 & 0.14 \\
\hline Australia & 0.38 & -0.20 & 0.04 & Mexico & 0.72 & -0.07 & 0.02 \\
\hline Austria & 2.12 & -0.40 & 0.09 & Morocco & 0.21 & 0.14 & 0.09 \\
\hline Bangladesh & -1.32 & -0.39 & 0.09 & Mozambique & 1.17 & -0.65 & 0.25 \\
\hline Belgium & 1.58 & -0.46 & 0.07 & Netherlands & 0.94 & -0.27 & 0.04 \\
\hline Botswana & 1.71 & -0.07 & 0.21 & New Zealand & 1.00 & -0.16 & 0.02 \\
\hline Brazil & 0.24 & -0.22 & 0.09 & Peru & 0.41 & -0.21 & 0.09 \\
\hline Bulgaria & 0.14 & -0.04 & 0.05 & Philippines & 1.12 & -0.21 & 0.11 \\
\hline Canada & 0.90 & -0.03 & 0.00 & Poland & 0.35 & 0.13 & 0.02 \\
\hline Chile & 0.74 & -0.25 & 0.07 & Portugal & 0.68 & -0.28 & 0.07 \\
\hline China & 0.18 & -0.10 & 0.02 & Romania & 0.87 & -0.12 & 0.04 \\
\hline Colombia & 0.49 & -0.38 & 0.07 & Russia & 0.50 & -0.19 & 0.02 \\
\hline Croatia & 1.55 & -0.06 & 0.04 & Singapore & -9.66 & 0.00 & 0.26 \\
\hline Cyprus & 2.11 & -0.29 & 0.12 & Slovakia & 0.78 & -0.36 & 0.05 \\
\hline Czech Rep. & 0.66 & -0.26 & 0.02 & Slovenia & 0.57 & -0.11 & 0.05 \\
\hline Denmark & 1.19 & -0.21 & 0.02 & South Africa & 0.16 & 0.98 & 0.02 \\
\hline Estonia & 2.19 & -0.13 & 0.05 & Spain & 0.52 & -0.12 & 0.04 \\
\hline Finland & 0.63 & -0.20 & 0.11 & Sri Lanka & 1.13 & -0.46 & 0.23 \\
\hline France & 1.35 & -0.42 & 0.04 & Sweden & 0.93 & -0.20 & 0.04 \\
\hline Germany & 0.65 & -0.09 & 0.02 & Switzerland & 0.76 & 0.00 & 0.07 \\
\hline Greece & 1.17 & -0.29 & 0.02 & Taiwan & 0.14 & 0.42 & 0.05 \\
\hline Hong Kong & 0.82 & 0.00 & 0.11 & Tanzania & 0.57 & -0.30 & 0.07 \\
\hline Hungary & 0.61 & -0.72 & 0.05 & Thailand & -0.24 & -0.61 & 0.05 \\
\hline India & -0.71 & 1.32 & 0.04 & Tunisia & -3.08 & 8.81 & 0.09 \\
\hline Indonesia & 0.45 & -0.25 & 0.02 & Turkey & 0.48 & 1.89 & 0.04 \\
\hline Ireland & 2.49 & -0.46 & 0.04 & Uganda & 0.63 & -0.12 & 0.07 \\
\hline Italy & -1.43 & -0.31 & 0.05 & United Kingdom & 0.37 & -0.27 & 0.05 \\
\hline Japan & 0.09 & 0.10 & 0.07 & United States & 0.20 & 0.08 & 0.02 \\
\hline Korea & 0.42 & 3.85 & 0.11 & Uruguay & 0.37 & -0.18 & 0.04 \\
\hline Latvia & 1.51 & -0.33 & 0.11 & Venezuela & 0.53 & -0.51 & 0.07 \\
\hline Lithuania & 0.18 & -0.07 & 0.07 & Vietnam & -0.23 & 2.16 & 0.05 \\
\hline Luxembourg & 1.20 & -0.19 & 0.07 & Zambia & 1.11 & -0.81 & 0.23 \\
\hline Madagascar & 1.04 & -0.35 & 0.19 & Zimbabwe & 0.47 & 0.21 & 0.07 \\
\hline Malawi & 0.95 & -0.75 & 0.11 & & & & \\
\hline
\end{tabular}

Notes: This table reports the welfare and competitive effects of unilateral tariff changes by each country on their respective domestic market. For the counterfactuals, "10\% $\Uparrow$ " represents when each country increases all tariffs in all industries by $10 \%$, and "All $\Downarrow$ " represents each country removing all tariffs that remained post-2000. The higher-column labels $\% \Delta E V_{l}$ and "Share $\widehat{a}_{i l}<0$ " report changes to welfare and competition for each labeled counterfactual. The results for aggregated regions are available upon request. 
Table 5: Effects of a 10\% Increase in all tariffs

\begin{tabular}{|c|c|c|c|c|c|}
\hline Country & $\begin{array}{l}\% 4 \\
\bar{k}_{i}\end{array}$ & $\begin{array}{l}V_{l} \\
\quad k_{i j}\end{array}$ & Country & $\begin{array}{l}\% \Delta \\
\bar{k}_{i}\end{array}$ & $\begin{array}{ll}E V_{l} & \\
& k_{i j}\end{array}$ \\
\hline Albania & 1.67 & 1.71 & Malaysia & -2.86 & -1.35 \\
\hline Argentina & -0.17 & -0.17 & Malta & 23.63 & 24.36 \\
\hline Australia & -1.00 & -1.08 & Mexico & -0.16 & -0.05 \\
\hline Austria & 1.62 & 1.82 & Morocco & -1.16 & -1.22 \\
\hline Bangladesh & 1.14 & 0.38 & Mozambique & 0.48 & 0.33 \\
\hline Belgium & -0.61 & -0.18 & Netherlands & -0.36 & 0.04 \\
\hline Botswana & -2.74 & -2.83 & New Zealand & -0.96 & -1.03 \\
\hline Brazil & -0.45 & -0.46 & Peru & 0.04 & 0.15 \\
\hline Bulgaria & -0.14 & -0.11 & Philippines & -3.37 & -3.90 \\
\hline Canada & -0.55 & -0.52 & Poland & 0.14 & 0.18 \\
\hline Chile & -1.92 & -2.02 & Portugal & 0.31 & 0.54 \\
\hline China & -0.96 & -0.95 & Romania & 0.70 & 0.74 \\
\hline Colombia & -0.32 & -0.27 & Russia & -1.08 & -0.95 \\
\hline Croatia & 2.02 & 1.92 & Singapore & -20.88 & -27.66 \\
\hline Cyprus & 0.91 & 0.62 & Slovakia & -1.46 & -1.28 \\
\hline Czech Rep. & -1.35 & -1.27 & Slovenia & -4.22 & -3.96 \\
\hline Denmark & -1.48 & -1.35 & South Africa & -1.61 & -1.35 \\
\hline Estonia & 2.07 & 1.89 & Spain & -1.21 & -1.03 \\
\hline Finland & -0.59 & -0.57 & Sri Lanka & -0.54 & 0.67 \\
\hline France & 0.02 & 0.40 & Sweden & -0.83 & -0.75 \\
\hline Germany & -0.04 & 0.16 & Switzerland & -1.88 & -2.03 \\
\hline Greece & 1.52 & 1.66 & Taiwan & -7.05 & -5.98 \\
\hline Hong Kong & -4.53 & -6.17 & Tanzania & 0.06 & 0.28 \\
\hline Hungary & -1.07 & -1.02 & Thailand & -10.37 & -11.79 \\
\hline India & -2.44 & -2.63 & Tunisia & -6.46 & -5.00 \\
\hline Indonesia & -2.50 & -2.92 & Turkey & -3.44 & -3.00 \\
\hline Ireland & -1.85 & -1.41 & Uganda & -0.09 & -0.2 \\
\hline Italy & -2.82 & -2.44 & United Kingdom & -0.33 & 0.04 \\
\hline Japan & 1.03 & 1.00 & United States & -0.15 & -0.15 \\
\hline Korea & -1.77 & -1.61 & Uruguay & -0.33 & -0.37 \\
\hline Latvia & -5.97 & -4.99 & Venezuela & 0.13 & 0.19 \\
\hline Lithuania & -1.74 & -1.06 & Vietnam & -30.75 & -31.62 \\
\hline Luxembourg & -1.02 & 0.40 & Zambia & 0.83 & 0.81 \\
\hline Madagascar & -0.57 & -0.39 & Zimbabwe & -1.05 & -0.47 \\
\hline Malawi & -11.16 & -15.74 & & & \\
\hline
\end{tabular}

Notes: This table reports the welfare effects $\left(\% \Delta E V_{l}\right)$ of a $10 \%$ increase in tariffs by all markets. For the counterfactuals, $\bar{k}_{i}$ represents no shape heterogeneity within industries, and $k_{i j}$ represents counterfactuals with shape heterogeneity within industries. The results for aggregated regions are available upon request. 
Table 6: Welfare Effects of Trade Agreements $\left(\% \Delta E V_{l}\right)$

\begin{tabular}{|c|c|c|c|c|c|c|c|}
\hline Country & $\begin{array}{r}\text { Reverse } \\
\text { UR Tariffs }\end{array}$ & $\begin{array}{r}\text { Remove } \\
\text { All Tariffs }\end{array}$ & $\mathrm{TPP}$ & Country & $\begin{array}{r}\text { Reverse } \\
\text { UR Tariffs }\end{array}$ & $\begin{array}{r}\text { Remove } \\
\text { All Tariffs }\end{array}$ & TPP \\
\hline Albania & -1.00 & 1.23 & 0.02 & Malaysia & 2.95 & -2.40 & -0.63 \\
\hline Argentina & -0.38 & 0.10 & 0.00 & Malta & 12.87 & 1.27 & 0.55 \\
\hline Australia & 0.04 & 0.13 & -0.01 & Mexico & 0.38 & 0.11 & 0.01 \\
\hline Austria & 0.01 & -0.08 & 0.04 & Morocco & -0.33 & 0.88 & 0.08 \\
\hline Bangladesh & -3.66 & 0.87 & 0.00 & Mozambique & -1.90 & -0.07 & -0.02 \\
\hline Belgium & -0.01 & 0.33 & 0.11 & Netherlands & 0.13 & 0.32 & 0.06 \\
\hline Botswana & 4.23 & -7.10 & 0.00 & New Zealand & 1.21 & 0.22 & 0.11 \\
\hline Brazil & -0.16 & -0.02 & 0.00 & Peru & -0.62 & 0.12 & 0.07 \\
\hline Bulgaria & -0.40 & 0.25 & 0.01 & Philippines & -1.67 & 0.65 & 0.00 \\
\hline Canada & -0.18 & 0.12 & 0.03 & Poland & -0.32 & 0.55 & 0.06 \\
\hline Chile & 0.21 & 0.19 & -0.08 & Portugal & 0.91 & -0.75 & 0.03 \\
\hline China & -0.38 & 0.42 & 0.03 & Romania & 0.45 & 0.64 & 0.08 \\
\hline Colombia & -0.17 & 0.01 & 0.01 & Russia & -0.32 & 0.44 & 0.00 \\
\hline Croatia & -0.23 & -0.19 & 0.05 & Singapore & -16.79 & 7.19 & 0.13 \\
\hline Cyprus & -1.46 & -0.83 & 0.00 & Slovakia & -1.42 & 0.55 & 0.01 \\
\hline Czech Rep. & -1.36 & 0.79 & 0.03 & Slovenia & -2.63 & 2.21 & 0.00 \\
\hline Denmark & -0.65 & 0.35 & 0.00 & South Africa & -2.72 & 1.91 & 0.01 \\
\hline Estonia & 3.98 & -1.07 & -0.04 & Spain & -0.95 & 0.93 & 0.02 \\
\hline Finland & 0.36 & -0.21 & 0.02 & Sri Lanka & 2.56 & -0.24 & -0.01 \\
\hline France & -0.14 & 0.23 & 0.05 & Sweden & -0.88 & -0.11 & 0.04 \\
\hline Germany & 0.08 & 0.26 & 0.03 & Switzerland & -1.69 & 1.01 & -0.01 \\
\hline Greece & 0.22 & -0.01 & 0.03 & Taiwan & -3.45 & 1.51 & -0.09 \\
\hline Hong Kong & -4.56 & 1.73 & -0.08 & Tanzania & -0.67 & 0.26 & -0.02 \\
\hline Hungary & -0.29 & -0.38 & 0.01 & Thailand & -2.28 & 1.66 & -0.15 \\
\hline India & -4.02 & 2.12 & -0.02 & Tunisia & -1.06 & 7.00 & 0.07 \\
\hline Indonesia & 2.94 & -0.01 & -0.16 & Turkey & -1.37 & 1.63 & 0.02 \\
\hline Ireland & 1.26 & 1.38 & 0.01 & Uganda & -0.68 & 1.62 & -0.11 \\
\hline Italy & -3.95 & 2.70 & 0.03 & United Kingdom & 0.04 & 0.07 & 0.04 \\
\hline Japan & 0.26 & -0.03 & 0.09 & United States & -0.17 & 0.12 & 0.00 \\
\hline Korea & 2.47 & 4.58 & 0.02 & Uruguay & -0.58 & 0.04 & -0.04 \\
\hline Latvia & -2.07 & -0.45 & 0.09 & Venezuela & -0.16 & -0.50 & 0.06 \\
\hline Lithuania & 4.39 & -1.36 & 0.01 & Vietnam & -18.13 & 8.49 & 0.63 \\
\hline Luxembourg & 2.20 & 0.32 & 0.06 & Zambia & 1.30 & -0.49 & -0.01 \\
\hline Madagascar & 2.41 & -2.26 & 0.04 & Zimbabwe & -1.76 & 1.04 & -0.02 \\
\hline Malawi & -6.77 & 1.56 & -0.02 & & & & \\
\hline
\end{tabular}

Notes: This table reports the effects of three large multilateral shocks. The first column reports the welfare effects of reversing 1994-2000 tariff cuts. The second column reports the welfare effects of removing all post-2000 tariffs. The third column reports the effects of tariff reductions within the proposed Transpacific Partnership. The results for aggregated regions are available in the online appendix. 